\title{
DOBRAS ESTRUTURAIS: RUPTURA GENERATIVA EM GRUPOS SOBREPOSTOS ${ }^{1}$
}

\author{
STRUCTURAL FOLDS: GENERATIVE DISRUPTION IN OVERLAPPING GROUPS \\ PLIEGUES ESTRUCTURALES: RUPTURA GENERATIVA EN GRUPOS SUPERPUESTOS
}

\begin{abstract}
RESUMO
Os grupos empresariais enfrentam um desafio duplo: reconhecer e implementar novas ideias. O presente artigo sugere que o empreendedorismo está mais relacionado com a geração de novos conhecimentos, por meio da recombinação de recursos, do que com a importação de ideias. Em contraste com a perspectiva "intermediação mais fechamento", enfocamos a sobreposição de estruturas coesas de grupos. Ao analisar processos de intercoesão de redes, identificamos uma topologia de rede distinta: a dobra estrutural. Os atores de uma dobra estrutural são membros de múltiplos grupos, o que facilita o acesso familiar a diversos recursos. Nosso conjunto de dados permite observar laços pessoais entre as 1.696 maiores empresas húngaras de 1987 a 2001. Primeiro, testamos se dobras estruturais contribuem para o desempenho de grupos. Segundo, como o empreendedorismo é um processo de ruptura generativa, testamos a contribuição das dobras estruturais para a instabilidade do grupo. Terceiro, passamos de métodos dinâmicos à análise histórica de redes, e demonstramos que a coerência é uma propriedade de genealogias entrelaçadas de coesão, construídas por meio de repetidas separações e reunificações.
\end{abstract}

PALAVRAS-CHAVE Dobra estrutural, genealogia de coesão, intermediação, empreendedorismo, teoria de redes.

Balázs Vedres vedresb@gmail.com

Professor do Department of Sociology and Social Anthropology, Central European University - Budapest, Hungary

David Stark dcs36@columbia.edu

Professor do Departament of Sociology, Columbia University - New York - NY, Estados Unidos

Artigo Convidado. Aprovado em 23.04.2010

Revisão Técnica de Charles Kirschbaum. Editor Científico: Felipe Zambaldi

ABSTRACT Entrepreneurial groups face a twinned challenge: recognizing and implementing new ideas. We argue that entrepreneurship is less about importing ideas than about generating new knowledge by recombining resources. In contrast to the brokerage - plus - closure perspective, we address the overlapping of cohesive group structures. In analyzing the network processes of intercohesion, we identify a distinctive network topology: the structural fold. Actors at the structural fold are multiple insiders, facilitating familiar access to diverse resources. Our data set records personnel ties among the largest 1,696 Hungarian enterprises from1987 to 2001. First, we testwhether structural folding contributes to group performance. Second, because entrepreneurship is a process of generative disruption, we test the contribution of structural folds to group instability. Third,wemove fromdynamicmethods to historical network analysis and demonstrate that coherence is a property of interwoven lineages of cohesion, built up through repeated separation and reunification.

KEYWORDS Strucutral fold, lineages of cohesion, brokerage, entrepreneurship, network theory.

RESUMEN Grupos empresariales enfrentan un doble desafío: reconocer e implementar nuevas ideas. El presente artículo sugiere que el emprendedorismo está más relacionado a la generación de nuevos conocimientos, a través de recombinación de recursos, que a la importación de ideas. En contraste con la perspectiva "intermediación y cierre", abordamos la superposición de estructuras cohesas de grupos. Al analizar procesos de intercohesión de redes, identificamos una topología de red distinta: el pliegue estructural. Los actores de un pliegue estructural son miembros de múltiples grupos, lo que facilita el acceso familiar a diversos recursos. Nuestro conjunto de datos permite registrar lazos personales entre las 1.696 mayores empresas húngaras, entre 1987 y 2001. Primero, testeamos si pliegues estructurales contribuyen al desempeño de grupos. Segundo, dado que el emprendedorismo es un proceso de ruptura generativa, testeamos la contribución de los pliegues estructurales a la inestabilidad del grupo. Tercero, pasamos de métodos dinámicos al análisis histórico de redes, y demostramos que la coherencia es una propiedad de genealogías entrelazadas de cohesión, construidas por medio de repetidas separacies y reunificaciones.

PALABRAS CLAVE Pliegue estructural, genealogía de cohesión, intermediación, emprendedorismo, teoría de redes. 
Os grupos empresariais enfrentam dois desafios-chave em seu modo empresarial de operação: reconhecer recursos de ideias inovadoras e assegurar seus meios de implementação. Opiniões recentes sugerem que os laços de conectividade de intermediação fora do grupo oferecem contato com novas ideias no ambiente e que laços de coesão de fechamento dentro do grupo oferecem compreensão mútua e confiança para a implementação (BURT, 2005; OBSTFELD, 2005; UZZI E SPIRO, 2005). Considerando que essa perspectiva "intermediação mais fechamento" imagina a inovação como a importação e implementação de ideias, oferecemos um conceito alternativo de empreendedorismo como recombinação. Em nossa visão, as ideias verdadeiramente inovadoras - no primeiro exemplo, uma clara conceituação do próprio problema - não estão livres de flutuação fora do grupo.

Em vez de importar ideias ou informações, o desafio aqui é produzir conhecimento. Segue-se que o trabalho de recombinação que produz novos conhecimentos pede intensa interação e profundo acesso pessoal às bases de conhecimento e recursos produtivos, ao contrário do contato remoto e de acessos eventuais. A partir dessa perspectiva, o empreendedorismo, como uma habilitação de capacidade, comprova ser produtivo não tanto por encorajar a fluidez de informação ou a confirmação de identidades fixas, mas pelo favorecimento do atrito gerador e produtor que rompe com as categorias recebidas de "negócios como de costume" e permite a redefinição, reimplantação e recombinação de recursos (STARK, 2009). Contudo, uma simples expansão da associação a um grupo coeso não seria o suficiente: a recombinação requer interação por meio $\mathrm{d}$ a diversidade.

Portanto, discutimos aqui que o empreendedorismo no contexto de grupo de negócios é conduzido pela interseção de grupos coesos onde os atores têm acesso familiar a diversos recursos disponíveis para recombinação. Por meio d esse argumento, baseamo-nos na idéia de Simmel ([1922] 1964), que diz que a associação a grupos coesos pode se sobrepor. Com um método que nos permite identificar grupos coesos - contudo não exclusivos - trazemos um foco teórico para a distinta posição estrutural em sua interseção. Nosso conceito de dobra estrutural é uma contraparte teórica ao conceito de buraco estrutural de Burt (1992) com diferentes propriedades de rede. Correspondendo à nossa diferente compreensão de processo inovador e suas bases estruturais, a intercoesão, como uma participação mútua em diversos grupos coesos, oferece a necessária familiaridade e diversidade para o acesso e para a ação por meio dete uma topografia de rede distinta que não é um somatório de intermediação e fechamento.
Ainda discutimos que o empreendedorismo não possui apenas propriedades estruturais dentro de uma dimensão sincrônica, mas também propriedades dinâmicas ao longo da dimensão temporal. Especificamente, estruturas empresariais não são apenas criativas, mas também podem ser de ruptura. Por isso, nossa dupla tarefa é analisar características estruturais que predizem o desempenho do grupo $e$ analisar quando e como estas mesmas características estruturais contribuem ou debilitam a existência continuada do próprio grupo.

Propomos a rede de análises históricas como uma nova perspectiva vantajosa pela qual reexaminaremos a essência ou constituição da própria "coletividade". A fotografia instantânea convencional gráfica da análise de rede não distingue coletividades robustas ou estáveis de alinhamentos transitórios; isto apenas permite a distinção entre regiões de redes mais densas ou mais esparsas. Com esta estrutura convencional, é tentador focar apenas em regiões mais densas como estruturas de coesão onde forças sólidas de determinação estrutural mantêm os membros unidos. Uma vez que pensamos em grupos como histórias de coesão, entretanto, podemos afrouxar o efeito conceitual de estruturas determinativas e conceber grupos como locais e instrumentais para a atividade agêntica (SEWELL, 1992). Podemos reconhecer grupos, independente das perdas temporárias em densidade. $\mathrm{Na}$ verdade, normalmente achamos que a separação estratégica entre grupos de maiores unidades é apenas reconhecida através de análises históricas. Deste modo, nossas análises visam uma questão sociológica fundamental: o que é um grupo social através do tempo no que se refere às redes?

Nossa análise avança através de três testes. No primeiro teste, descobrimos que a intercoesão é um fator significante que explica o desempenho superior do grupo: grupos com mais dobras estruturais demonstram maior aumento de renda. Mudando para modelos dinâmicos, verificamos no segundo teste que as dobras estruturais preveem significantes rompimentos de grupos. Intercoesão empresarial eleva o desempenho, mas a um "custo" destabilização do grupo. Nossos resultados, portanto, sugerem que a intercoesão é duplamente generativa: no primeiro exemplo, suas tensões criativas de familiaridade e diversidade promovem o desempenho do grupo, enquanto no segundo exemplo, estas mesmas tensões fomentam uma ruptura criativa que produz a dispersão dos membros do grupo, que fica disponível para um novo reagrupamento.

Em um terceiro teste, vamos de um modelo dinâmico para uma análise de rede histórica para analisar a coerência dos grupos em suas repetidas reconstituições. Os grupos desestabilizados se espalham ao sabor dos ventos 
ou se reconstroem através de linhas padronizadas que poderiam indicar a existência de grupos de negócios, no próprio sentido de coletividades maiores e historicamente constituídas? Para resolver esta questão, desenvolvemos o conceito de genealogia de coesão como um constructo que captura as contínuas redes de ancestralidade das estruturas nucleares de coesão em seus modelos anteriores. Nossa abordagem promove uma agenda para desenvolver a análise da sequência social (STARK e VEDRES, 2006). Enquanto a análise da sequência tipicamente conceitua sequências como sendo isoladas e lineares, sequências de coesão são aqui conceituadas como interconectadas e ramificadas. Em nosso caso, a "estrutura de parentesco" dos grupos de negócios é dada pela reprodução e troca de membros entre grupos nucleares através das "gerações" (os anos em nosso estudo). Entendemos que grupos de negócios como coletividades históricas maiores mantêm sua coerência através de redes entrelaçadas.

A Hungria pós-socialista oferece um excelente caso para o exame da inovação organizacional e a evolução histórica dos grupos de negócios. Os deslocamentos e as incertezas que as empresas estatais submetidas à privatização enfrentavam, novas operações e subsidiárias estrangeiras raramente são exagerados. Com o colapso da Comecon (o sistema de negócios entre estados do bloco Soviético) seguido da dissolução da União Soviética, muitas empresas enfrentaram o colapso quase total de seus mercados, que um dia, foram confiáveis. Quando o quadro institucional das formas corporativas foi estabelecido em 1988, o número de corporações expandiu rapidamente (de um punhado a meio milhão, hoje). Redes de negócios e grupos de negócios emergiram rapidamente como experimentação organizacional e rapidamente ganharam velocidade para localizar ou gerar mercados para produtos do grupo e para proteger seus membros contra uma variedade de incertezas. Muitos estudos demonstraram a capacidade inovadora de empresas e grupos pós-socialistas de fazer uso de novas instituições corporativas, assim como propriedade cruzada, laços com a administração e estruturas de sustentação (STARK 1996; SPICER, MCDERMOTT e KOGUT 2000).

Neste contexto, a nova instituição de órgãos de fiscalização corporativa e conselhos administrativos oferecereu às empresas recursos confiáveis de informação, acesso às informações privadas sobre sucessos e falhas que ocorreram em outro lugar para lidar com desafios, e um mecanismo para a coordenação de ações entre negócios estratégicos aliados. Exigidos pela lei corporativa, a instituição era totalmente inovadora para os executivos húngaros. CEOs e outros gestores seniores que entrevistamos se lembraram de sua perplexidade ao participar de sua primeira reunião de conselho, mas também enfatizaram quão rapidamente as empresas compreenderam a possibilidade de partilhar diretores como uma oportunidade para coordenação estratégica.

Nossos conjuntos de dados documentam este processo de experimentação organizacional e as dinâmicas de formação de grupo e empreendedorismo. Coletamos nomes de todos os detentores de cargos econômicos da Hungria de 1987 a 2001, definindo todos os executivos da área econômica como gestores seniores, membros dos conselhos administrativos e conselhos fiscais das 1.696 maiores empresas. Com nossa lista de 72.766 nomes e as datas exatas de sua posse nestes conselhos, podemos construir os laços de pessoal que conectam estas grandes empresas para cada ano em nosso estudo. Nosso caso remonta ao momento exato em que empresas podiam adotar uma recém-legalizada, forma corporativa. ${ }^{2}$ Isto inclui períodos de incertezas nos negócios que envolviam privatização, recessão transformacional, mercantilização, a institucionalização de regulamentações econômicas, investimento direto estrangeiro maciço, assim como três eleições parlamentares.

\section{ESTRUTURAS DE REDE PARA ACESSO E AÇÃO}

Uma característica proeminente das redes de negócios é que as empresas se aglomeram em grupos coesos. Densos laços entre os membros do grupo, propõem-se, fornecem uma base para confiança e um meio de ação coordenada (USEEM, 1980; UZZI 1997). Os laços de coesão permitem que grupos implementem projetos além da capacidade de qualquer dada empresa (GRANOVETTER, 2005). O compartilhamento de risco junto a estes laços proteje os grupos de incertezas. Como o impacto de períodos abruptos de baixa é mitigado, a propagação de risco neste grupo de rede de negócios diminui a volatilidade dos lucros anuais (LINCOLN, GERLACH e AHMADJIAN, 1996).

Outra lógica afirma que grupos de negócios devem optar por renunciar à alta densidade dentro do grupo a favor da manutenção de laços mais fracos com as empresas fora do grupo. Tal estratégia de sacrifício da densidade a favor da diversidade economiza recursos de rede através da redução do número de laços redundantes (Burt 1992). Os laços de longa distância oferecem acesso a mais canais de informação fora do grupo, e esta diversidade oferece uma base para maior adaptabilidade. De acordo com esta lógica, a estratégia conservadora de coesão em grupo é uma adaptação pobre. Esta estratégia corre o risco de 
travar o grupo de negócios em sucessos iniciais, uma estratégia que rapidamente se tornará prejudicial em uma situação de rápidas mudanças onde o direcionamento da ruptura não pode ser previsto. A estratégia de defesa de fechamento do grupo arrisca a chance da criação de uma falsa sensação de segurança a ponto de quando a situação real pode não levar a um choque entre "sobrevivência" e "inovação", mas à busca pela inovação a fim de sobreviver.

Recentes desenvolvimentos em análises de redes sugerem uma terceira estratégia: ao invés de fortalecer laços dentro do grupo ou alcançar o lado de fora deste grupo, faça os dois. Alguns pesquisadores usam os termos "coesão" e "conectividade" para caracterizar esta estratégia (WATTS, 1999; MOODY e WHITE, 2003; UZZI e SPIRO, 2005); outros favorecem a terminologia de "fechamento" e "intermediação" (BURT, 2005, 2008; BAUM, MCEVILY e ROWLEY, 2007). Comum a tudo isso está a ideia de complementaridade destas propriedades distintas de redes, considerado como especialmente benéfica em casos onde o objetivo é a inovação. Intermediação/conectividade oferecem acesso a ideias e informações, mas em si faltam os meios para sua implementação. Fechamento/coesão oferecem os meios de coordenação, mas falta a diversidade para a descoberta. Juntos, eles podem compensar as limitações de cada um; Obstfeld (2005) os rotulou como "problema de ação" e "problema de idéia". Um exemplo dessa abordagem é o recente estudo feito por Uzzi e Spiro (2005), que demonstra que o sucesso dos musicais da Broadway (onde a inovação é a habilidade de produzir um "hit") é função de coesão suficiente (a continuidade na composição da "equipe" musical de um musical para outro) e conectividade (diversidade na composição de um de um musical para outro).

Nosso estudo dos grupos de negócios na Hungria faz uso desses recentes estudos como seu ponto de partida. Com Burt, Uzzi e outros, compartilhamos a noção de que o empreendedorismo (ou, de forma mais geral, a inovação) não é facilitado apenas por seus fechamentos/coesão ou intermediação/conectividade, sozinhos. Porque concordamos que a inovação envolve a combinação de familiaridade e diversidade, da mesma forma que procuramos identificar características de estruturas específicas que promovem estes processos sociais. Entretanto, nos afastamos do consenso atual por meio da proposição de uma perspectiva de estruturas empresariais que não envolve um somatório das dicotomias convencionais. Em vez disso, ao elaborar a teoria da próxima seção, desenvolvemos uma concepção de intercoesão, uma estrutura de rede distinta construída através da interseção de grupos coesos.
Pelo fato de vermos o empreendedorismo como disruptivo, assim como criativo, estamos atentos à conclusão de Uzzi e Spiro (2005), que diz que a inovação requer algum remanejamento de grupos. Os grupos muito estáveis (um musical da Broadway formado com os mesmos membros que trabalharam juntos em um musical anterior) e grupos altamente instáveis (um musical onde poucos membros já trabalharam juntos antes) são menos propensos a produzir uma inovação do que grupos que misturam membros com filiação anterior e filiações inovadoras. Com esta ideia em mente, seguimos para o próximo passo analítico: existirá uma característica estrutural que possa prever um desempenho de sucesso e também explicar as dinâmicas da formação e dissolução do grupo?

\section{INTERCOESÃo}

Para resolver esta questão, devemos primeiro identificar os grupos relevantes em termos de rede. Nosso caso difere daqueles de Burt e Uzzi, para quem os limites de grupo (p. ex. os membros de um projeto de equipe, os membros de um musical) são dados anteriormente à análise. Os grupos de negócios na Hungria - ao contrário das economias da Ásia oriental, onde os analistas podem referir-se aos diretórios listando os membros do japonês keiretsu ou do sul-coreano chaebol - não existem como lugares nomeados na paisagem econômica.

Adotamos a medida de coesão para identificar os componentes dos grupos de negócios, utilizando o princípio teórico orientador de que estruturas de grupos coesos não necessariamente precisam ser exclusivos. ${ }^{3}$ Isto é, estamos deliberadamente afinados para as possibilidades de que as estruturas de rede podem ser coesas e sobrepostas. Como observado por Simmel (1964) em Web of Group Affiliations, uma pessoa é frequentemente membro de mais de um grupo coeso em um determinado período. Para Simmel, tal associação a múltiplos grupos era uma fonte tanto de individuação para a pessoa como de integração social para as coletividades maiores envolvidas. Em nossa população de empresas na Hungria, podemos encontrar, por exemplo, uma usina ligada a outras usinas em um grupo coeso, enquanto também ligada de forma coesa a distribuidores de energia e minas de carvão, ligadas a outras empresas da indústria pesada em um diferente grupo coeso, e associado a um grupo com bancos.

Desenvolvemos o conceito de intercoesão para nos referirmos à interpenetração mútua de estruturas coesas. A Figura 1 ilustra a estrutura de intercoesão em contraste com intermediação e fechamento. Ela também 
apresenta a distinta posição de rede, dobras estruturais, na interseção. ${ }^{4}$ Os atores de uma dobra estrutural são os membros de múltiplos grupos, que participam de densos laços de coesão que oferecem familiaridade com as operações dos membros de seu grupo. Pelo fato de serem membros de mais de um grupo coeso, eles possuem acesso familiar a diversos recursos. Essa combinação de familiaridade e diversidade facilita o trabalho de recombinação de recursos. Como o nó, que é comum a grupos múltiplos, as dobras estruturais são recursos para os próprios grupos. A intercoesão significa fechamento sem que o grupo tenha sido fechado; isto é, uma coesão generativa sem insularidade.

Nossa identificação de processos distintamente intercoesos (ao contrário de uma operação aditiva da estrutura de grupo de laços internos e a estrutura de laços de grupos externos) repousa sobre as diferenças conceituais acerca do empreendedorismo. Para os adeptos da escola aditiva, a inovação é basicamente conceitualizada como um processo de germinação: de ponte ou laços de intermediação que trazem as sementes de ideias e informações para o solo fértil de relações de confiança de coesão. Não temos dúvidas de que ideias e informações são normalmente vitais; nossa questão é se a atividade de recombinação produtiva envolve apenas (ou até mesmo primariamente) recursos que podem fluir ou circular.

Com Schumpeter, concebemos o empreendedorismo como uma recombinação, ${ }^{5}$ um processo mais complexo do que a importação e a implementação de ideias inovadoras. Em nosso ponto de vista, o problema de ideia é na verdade um problema de ação. Isto é, as ideias mais inovadoras não estão "por aî" no ambiente do grupo. Em vez de esperar que sejam encontradas, elas devem ser criadas (KOGUT e ZANDER, 1992). Uma coisa é reconhecer um padrão já identificado, mas outra completamente diferente é fazer uma nova associação. Nesse contexto, o processo de inovação é paradoxal, porque envolve uma curiosa função cognitiva de reconhecer o que ainda não é formulado como uma categoria (STARK, 2009). Assim como John Dewey $(1938,1998)$ e os pragmáticos defendiam, é apenas no processo de tentar transformar o mundo que novos problemas chagam a ser formulados. A criação de recombinações inovadoras é por si só um tipo de produção que requer a coordenação e a cooperação de diferentes comunidades.

Em seu estudo de desenvolvimento de novos produtos para telefones celulares, moda jeans e equipamentos médicos, Lester e Piore (2004) demonstram que cada um de seus casos de inovação radical envolve combinações por meio de campos distintos: os jeans da moda são o casamento da tradicional roupa de operário com a tecnologia de lavagem tomada de hospitais e hotéis; os equipamentos médicos baseiam-se tanto nas ciências biológicas como na prática médica; e os telefones celulares recombinam, de forma inovadora, as tecnologias de rádio e telefone. Eles concluem que "sem uma integração por meio dos limites que separam esses diferentes campos, não haveria nenhum novo produto" (LESTER e PIORE 2004, p. 14-15). ${ }^{6}$

Para nós, o importante dessa citação é a "integração que atravesse os limites". Lester e Piore não fazem menção a "contatos" através de limites, porque isso não é o suficiente para que diferentes comunidades estejam em contato. A inovação recombinante requer que elas interajam. Por esses motivos, o convencional emparelhamento de acesso à diversidade é insuficiente. O profundo acesso para a criação de novos problemas, novos conhecimentos e novas capacidades (ao contrário da transferência de ideias já aceitas) requer uma confiança considerável, consequentemente, familiaridade. Tal acesso só pode ser obtido por meio dos membros internos aceitos pelos grupos. Portanto, propomos que a recombinação produtiva no nível grupal requer acesso pessoal a recursos que não podem ser fornecidos por meio de um canal restrito dos estreitos laços de ponte e intermediação. ${ }^{7}$

Figura 1 - A estrutura de intercoesão em contraste com intermediação e fechamento

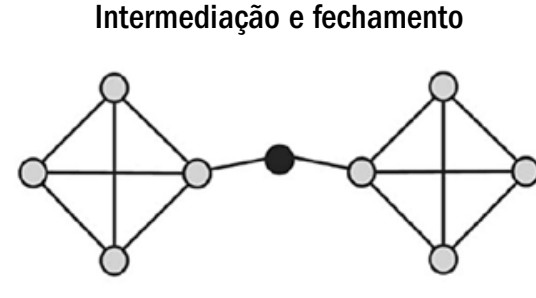

Buraco estrutural

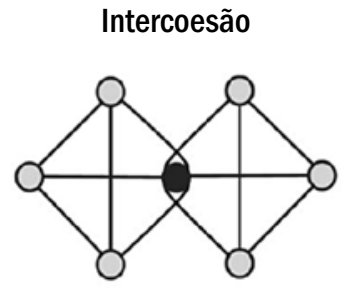

Dobra estrutural 
Contudo, esses laços não podem ser tão coesos que constituam um único grupo: para poder reconhecer o potencial para novas recombinações, o empreendedorismo requer acesso a diversos grupos de recursos ${ }^{8}-$ acesso que seja possível apenas ao se associar a dois ou mais grupos coesos. As distintas propriedades das dobras estruturais fornecem mecanismos para chegar a diversas familiaridades necessárias para o reconhecimento de recursos e para a sua recombinação produtiva.

Para testar essas ideias, correlacionamos o desempenho de grupos e o seu grau de intercoesão. Esperamos que grupos com mais dobras estruturais tenham um melhor desempenho do que aqueles mais insulares.

\section{INSTABILIDADE E COERÊNCIA}

O estabelecimento de correlações entre estruturas e desempenho em um contexto transversal deixa a questão de durabilidade sem resposta: os laços são transitórios ou são um indicativo de um padrão sustentável e autogenerativo $?^{9}$ Ao testar se a intercoesão leva o aumento do desempenho, aprofundaremos a análise para saber se essa mesma estrutura é autoperpetuadora ou autodestrutiva. De uma perspectiva teórica, dobras estruturais são pontos de tensão em que múltiplas rotinas de operação e esquemas para a organização de recursos estão operando. Assim como as localizações proeminentes de reestruturação agêntica, tais estruturas sociais sobrepostas podem ser o motor de uma mudança social originada internamente (SEWELL, 1992). ${ }^{10}$

Nosso exame do papel da intercoesão na dinâmica da evolução do grupo provém de nossa concepção de empreendedorismo. Como observou Schumpeter (2003), o empreendedorismo, ao favorecer recombinações inovadoras, também contribui para a "destruição criativa". Expresso em termos analíticos de rede: as estruturas empresariais são suscetíveis de desestabilizar grupos. Como sugerem as conclusões de Uzzi e Spiro (2005), a estabilidade em si não é o resultado mais favorável; na verdade, alguma ruptura pode ser benéfica. Nós, portanto, testamos não apenas se as tensões criativas da familiaridade de intercoesão e diversidade melhoram o desempenho no primeiro exemplo, mas também se essas mesmas tensões fomentam a ruptura criativa que dispersa membros do grupo, que ficam então disponíveis para reagrupamentos futuros. Esperamos que as oportunidades de recombinação oferecidas por dobras estruturais terão o efeito de melhora no desempenho ao nível de grupo. Esperamos ainda que esses benefícios custem a estabilidade do grupo.
A associação sobreposta pode ser disruptiva para a coordenação de um grupo, as relações de confiança mútua e um senso de justiça. Aqueles com múltiplas conexões coesas podem parecer seguir estratégias que não são transparentes para aqueles com uma única associação, situação essa que pode impedir a coordenação. Em face das ambíguas lealdades da dobra estrutural, outros membros podem suspeitar estar sendo explorados ou manipulados; a falta de compromisso e tempo investido por aqueles com múltiplas associações a um dado grupo pode levar a uma disfunção ao nível do grupo, talvez ao rompimento e à fragmentação. Esperamos, então, que a intercoesão seja negativamente correlacionada à estabilidade de coesão do grupo.

Se a intercoesão representa um processo de ruptura generativa, não seriam os grupos de negócios forçados a escolher entre a busca da estabilidade e o alto desempenho? A perspectiva histórica sugere a alternativa de que os grupos de negócios mantêm a fragmentação dentro de limites gerenciáveis. Visto em uma dinâmica anual, esperamos encontrar um sistema de turnover de pertencimento expresso em um fluxo considerável. Mas a própria noção de grupo de negócios (e a literatura em grupos de negócios duradouros) sugere algum grau de coerência que persiste mais do que simplesmente de um ano para o outro (MIZRUCHI e STEARNS, 1988; GRANOVETTER, 2005). Em outras palavras, pode uma instabilidade considerável ser enquadrada sob o conceito de grupo de negócios concebido como uma entidade coerente? Para resolver essa questão, aplicamos uma análise histórica para complementar nossa análise dinâmica (ano a ano).

Do nosso ponto de vista, o conceito de grupo de negócios não é apenas um constructo analítico de rede; é um constructo de rede histórica. Dessa perspectiva, as estruturas de coesão de grupo em um quadro sincrônico são os blocos de construção de uma coletividade maior, constituindo o grupo de negócios com um período de tempo histórico mais extenso. Esses grupos nucleares podem ser conectados através do tempo a outros grupos, pelo intercâmbio de membros. Ao traçar esses laços, podemos construir um objeto histórico-sociológico moldado pelos padrões de ancestralidade comum. Em outras palavras, vamos de grupos nucleares às amplas "estruturas de parentesco" da organização empresarial.

Para identificar os modelos dessas estruturas de parentesco, desenvolvemos um conceito de genealogias de coesão por meio do qual traçamos redes de continuidade ancestral que chegam a cerca de 12 anos atrás. Nossa visão é que grupos nucleares que dividem uma ancestralidade podem estar próximos uns dos outros, conectados pelo 
compartilhamento intercoesivo de associados e uma linha entrelaçada comum de ascendência repetida (BRUDNER e WHITE, 1997; WHITE e JOHANSEN, 2005). Uma ancestralidade comum faz com que a formação de grupos seja mais fácil porque as rotinas de colaboração já são familiares. Essa familiaridade facilita o surgimento de dobras estruturais: grupos que dividem uma ancestralidade tendem ao menos ser propensos a ter rotinas e culturas de colaboração radicalmente diferentes, reduzindo desse modo os custos com coordenação de dobras estruturais.

Achamos que algumas genealogias de grupo de negócios operam por meio de uma única linha de sucessão. Ainda com a mesma frequência, achamos genealogias ainda mais complexas, aquelas que se ramificam em uma "geração" e se reconsolidam na próxima, e repetem esses processos de exploração e reconsolidação através dos anos sucessivos, com dobras estruturais atuando em um papel decisivo nessa divisão e retecelagem. Os grupos conectados pelo intercâmbio de membros operam como grandes coletividades que absorvem e, por isso, limitam a dispersão de membros de grupos desestabilizados e, desse modo, amenizam as rupturas causadas pela intercoesão. Em vez de se tornarem dispersos por uma grande gama de grupos em toda a economia, os grupos se dividem para se reunir a outros próximos a ele, reagrupando assim seus recursos em uma nova, mas familiar, combinação. A instabilidade, desse modo, se torna a recombinação de membros. Resumindo, a perda de membros é consistente com a coerência dos padrões: grupos de negócios lidam com as incertezas de seu ambiente ao manter a fragmentação dentro de limites gerenciáveis.

\section{DADOS E MÉTODOS}

\section{Dados}

O conjunto de dados que reunimos inclui as completas histórias de laços pessoais entre as maiores empresas da Hungria entre os anos 1987 e 2001. Definimos grandes empresas como aquelas listadas no ranking anual das empresas "Top 500" (baseadas nas receitas) para todos os anos de 1987 a 2001. Nossa regra de inclusão resulta em uma população de 1.696 empresas. Essa população de empresas representa mais de um terço dos empregos, cerca de metade do PIB húngaro, e quase toda a receita de exportação (FIGYELO, 2002).

Definimos os executivos da área econômica como gestores seniores, membros dos conselhos administrativos e conselhos fiscais dessas grandes empresas. Dados individuais de executivos da área econômica foram transcritos diretamente dos arquivos oficiais das 20 Varas de Registro em que as empresas húngaras são obrigadas a registrar informações sobre propriedade e pessoal. Esses arquivos de registro contêm os nomes e endereços residenciais de todos os gestores com direito de signatário (qualificados para assinar documentos que se tornam juridicamente vinculados à empresa). Os arquivos também listam os membros do conselho de diretores e do conselho fiscal. Para cada empresa, temos registrados os nomes de todos os signatários e membros do conselho que estiveram no cargo no período estudado, assim como as datas exatas de quando assumiram e deixaram o cargo. Nossos conjuntos de dados de executivos da área econômica contêm 72.766 nomes.

Além de executivos da área econômica, também coletamos os nomes de todos os detentores de cargos políticos da Hungria durante esse mesmo período. Para os anos entre 1990 e 2001, definimos como funcionários políticos todos os políticos eleitos, desde o primeiro-ministro até os membros do Parlamento, aos prefeitos de todos os municípios, inclusive os três mais altos cargos da hierarquia do Ministério Nacional (envolvendo ministros e seus representantes políticos e administrativos). Para o período anterior às eleições livres, definimos detentores de cargos políticos como todos os membros do Politburo e do Comitê Central do Partido Socialista dos Trabalhadores Húngaros, assim como os ministros do governo e seus representantes. ${ }^{11}$ Isso cobre a elite política sob o Estado socialista. Em todos os períodos, registramos a filiação aos partidos de cada cargo e as datas exatas de posse no cargo. Nosso conjunto de dados de detentores de cargos políticos que cobrem os anos 1987 a 2001 contém 16.919 nomes. Ao fundir essas listas de executivos da área econômica e política, podemos identificar precisamente, para qualquer dada empresa em qualquer mês, se a empresa teve um executivo da área econômica que também fora detentor de algum cargo político atual ou anterior filiado a algum partido político em particular.

Definimos duas empresas como tendo laços pessoais quando um gerente ou um membro do conselho de uma empresa se senta no conselho de outra empresa. Isso significa que estamos utilizando a projeção de uma modalidade (laços entre empresas) dos dados originais de dois modos (two-mode) (laços entre membros do conselho e conselhos) (BREIGER, 1974). Essa operação implica a perda de dados no sentido técnico, como um triângulo completamente conectado a empresas na projeção de um modo pode surgir de diferentes configurações na rede de dois modos (por exemplo, um diretor participando de três conselhos, ou três diretores participando de dois conse- 
lhos cada). Temos dois motivos principais para analisar a projeção de um modo, apesar da perda de detalhes de filiação.

A primeira consideração é que os laços pessoais são veículos para o estabelecimento de alianças de negócios (Mizruchi 1996; Burris 2005). Os atores dos negócios húngaros pós-socialistas veem o conselho de diretores do negócio como representantes das agências do governo, partidos políticos ou outras empresas parceiras.

É por meio desses laços pessoais que as empresas estabelecem alianças com outras empresas. Em nossas entrevistas, CEOs e outros gestores seniores falaram repetidamente sobre como estão atentos à composição do conselho. Ao falar, por exemplo, com o CEO de uma empresa-chave de um grupo de negócios que identificamos, perguntamos:

P. Por que os conselhos administrativos são importantes? R. Era necessário ter interligações entre conselhos a fim de solucionar os problemas. Meu antecessor aqui era apenas CEO, e, sem nenhuma interligação com conselhos, ele não tinha chance.

P. E os membros externos do conselho?

R. Para nossos sócios, quem eles veem em nosso conselho é importante. E quanto a mim, tenho problemas quando vejo pessoas desconhecidas em um conselho. Isso passa uma má impressão. O negócio pode ser um pouco estranho.

De forma similar, iniciamos a entrevista com o principal funcionário estratégico de um dos maiores bancos húngaros mostrando-lhe as tabelas que criamos, onde exibimos a história dos laços pessoais entre um banco e outras empresas. Perguntamos se ele nos diria por que o banco tinha estabelecido tais filiações. Após uma pausa, ele olhou diretamente em nossos olhos e respondeu com uma fria ênfase: "Esse é o meu negócio". Deixamos os papéis de lado e perguntamos se poderíamos falar em termos mais gerais. Ele declarou que as razões para a formação desses laços eram profundamente ligadas à busca de exclusividade, e continuou elaborando em detalhes como este realmente foi seu trabalho, seu negócio, para monitorar a composição de conselhos para detectar a formação e ruptura de alianças interorganizacionais na formação de grupos de negócios.

Nossa segunda consideração é que, embora os métodos e as técnicas para lidar com redes de um ou dois modos sejam extremamente diferentes, as substantivas diferenças entre os dois tipos de redes são menos pronunciadas.
As redes originalmente coletadas como de um modo normalmente têm um substrato de dois modos subjacente: uma rede de laços de amizade pode refletir em uma rede de filiação dois modos de círculos de pessoas e amizades (WATTS, 2004). No contexto dos negócios, o sistema de filiação pessoal com conselhos pode ser pensado como um substrato das alianças business-to-business. ${ }^{12}$

Registramos 'laços de pessoal' como simétricos, com uma data inicial e final para cada laço. Os modelos neste estudo fazem uso de uma resolução de tempo anual, com laços de pessoal registrados no último dia de cada ano. Definimos uma empresa como tendo filiação política quando um de seus executivos da área econômica é também um atual ou antigo detentor de cargo político, ${ }^{13} \mathrm{e}$ registramos a filiação partidária de determinado detentor de cargo político como o partido de afiliação da empresa. As afiliações políticas são, desse modo, laços pessoais que conectam empresas e partidos. ${ }^{14}$

Para cada empresa, também coletamos dados em suas receitas anuais, capitalização, empregos, classificação industrial, história de privatização e tipos de proprietários (Estado, entidade doméstica privada, ou proprietário estrangeiro).

\section{Identificação de grupos coesos com o método de percolação de cliques}

Para identificar grupos coesos, adotamos um método que inicia em localidades coesas, reconhece grupos independentemente do ambiente das redes globais e identifica dobras estruturais. Utilizamos o método de percolação de cliques (CPM - clique percolation method), desenvolvido por físicos para revelar a estrutura da comunidade de sobreposição das redes complexas (Palla e outros, 2005), método que recentemente demonstrou ser uma ferramenta adequada para a análise da evolução de grupos coesos (PALLA, BARABÁSI e VICSEK 2007).

O CPM começa com um clique de k nós, um k-clique. Em análises de redes sociais, os cliques eram normalmente rejeitados como métrica eficaz de coesão porque podem rapidamente se sobrepor a outros cliques. Por exemplo, uma rede de 10 nós pode ter dois cliques de nove que tem oito nós em sua sobreposição. O método padrão de resolver esse problema era analisar a coesão pelo registro do número de vezes que dois nós coparticiparam em cliques. O uso dessa similaridade como entrada para análises de agrupamento gerou regiões coesas excludentes não sobrepostas na rede (WASSERMAN e FAUST 1994).

Enquanto os procedimentos de modelagem padrão dividem a coesão, ao nível da rede global, mensurando similaridades ao nível do nó, o CPM é fundamentado em 
propriedades estritamente locais ao nível do clique. Em vez de considerar a sobreposição de um clique como um problema a ser solucionado, ele considera a sobreposição como o ponto inicial para a identificação de coesão (veja no apêndice detalhes sobre este método).

Embora tenha sido desenvolvido por físicos, o método melhora a abordagem padrão em análises de rede social e leva a um afastamento dos modelos convencionais. Mais importante para nossos propósitos, um grupo identificado pelo método CPM pode se sobrepor a outro grupo. Desse modo, o CPM está alinhado com Everett e Borgatti (1998), que reconheceram as limitações de partição forçado em vários algoritmos e apontaram a utilidade da adjacência dos cliques como uma solução teórica. ${ }^{15}$ Ao diminuir as associações a favor da adjacência dos cliques - por isso a apreensão de sobreposição de grupos - o CPM chega a um maior realismo sociológico que permite uma maior aproximação da noção de comunidade do que atinge o conceito de um clique sociométrico. Em uma comunidade social - ao contrário de uma rede de cliques - as pessoas não estão necessariamente conectadas a todas as outras. Utilizamos o CPM para identificar grupos em todos os anos de nosso conjunto de dados de 1987 a 2001.

\section{DESEMPENHO DO GRUPO}

Se a recombinação intercoesa contribui para o empreendedorismo e a inovação ao nível do grupo, os grupos de intercoesão deveriam superar os grupos exclusivos. A intercoesão contribui para o desempenho do grupo? Para responder a essa pergunta, primeiro precisamos identificar uma métrica adequada de desempenho e então isolar a contribuição de intercoesão para o desempenho.

Os lucros, embora seja um indicador de desempenho amplamente utilizado, possuem fundamentação questionável no cenário pós-socialista. Com altos impostos e alterações das regulamentações governamentais, os lucros podem facilmente ser manipulados - ou, eufemisticamente falando, "otimizados" - dependendo da regulamentação em vigor. Quando a maioria das empresas era submetida a programas de reestruturação, o lucro não era uma métrica prática para medir o desempenho da empresa. Em vez de produzir lucros imediatos, a chave para a sobrevivência era obter e manter os mercados e, desse modo, assegurar suas receitas. Optamos, portanto, em manter o foco nas dinâmicas da receita.

Consideramos o mais simples teste para fazer a correlação entre intercoesão no ano $t$ e aumento de receita do ano $t$ para o ano $t+1$. Para um dado grupo em um dado ano, a intercoesão é medida pelo número de dobras estruturais, isto é, o número de grupos com os quais aquele dado grupo se sobrepõe. O aumento da receita é o aumento da taxa ao nível de grupo, medida em termos reais (indexados à inflação). Essa correlação entre intercoesão e aumento de receita é significante $(P=.049)$ e positiva, embora fraca $(R=.088)$. Isso indica que grupos com mais dobras estruturais cresceram consideravelmente mais rápido.

Será que o aumento de uma receita em grupos com intercoesão ocorre apenas nas dobras estruturais? Se a intercoesão opera similarmente para a intermediação, esperamos que as empresas na interseção possam ver um aumento mais rápido em suas receitas, comparadas às empresas com apenas uma associação. Para responder a essa pergunta, ao lado da computação da correlação entre intercoesão e crescimento de receita no nível de grupo, também computamos a correlação entre o número de associações de grupos coesos e o crescimento de receita a nível individual. Essa correlação Pearson não é estatisticamente significante $(R=.039 ; P=.127)$, o que indica que os benefícios de intercoesão são realizados no nível de grupo e não aparecem distintamente no nível das empresas individuais que ocupam a dobra estrutural. ${ }^{16}$ Os mecanismos de dobras estruturais parecem se diferenciar de controle de acesso e intermediação, onde os benefícios possibilidades geradoras de receitas adicionais - adviriam da empresa de controle de acesso, expandindo os dois grupos.

Para testar os relacionamentos entre aumento e intercoesão e isolar esse relacionamento de outras variáveis explicativas de crescimento de receita, construímos modelos multivariados. Nosso objetivo é avaliar se existe um relacionamento significante entre intercoesão e crescimento, mesmo que apresentemos variáveis de processos de intracoesão (assim como tamanho do grupo ou homofilia), processos de extracoesão (primariamente aqueles de intermediação e ponte) e controlemos as variáveis, assim como a composição e eficiência da indústria.

Para cada grupo de nosso conjunto de dados, temos uma pontuação relativa ao crescimento de receita real. A partir dessa variável contínua, construímos duas variáveis categóricas dependentes, captando os processos distintos de declínio e crescimento de receita. Grupos mais empresariais deveriam atingir um desempenho mais alto, mas o empreendedorismo não garante o desempenho. Desse modo, também esperamos que mais grupos empresariais não sejam protegidos contra a diminuição do desempenho.

O declínio da receita registra se as receitas do grupo caíram durante o ano em questão. O alto crescimento de receitas registra se o grupo pertenceu aos $25 \%$ de grupos 
mais bem-sucedidos na amostra global (receitas para este quartil superior corresponderam a ao menos a $8 \%$ do crescimento anual, controlado pela inflação). Temos duas razões para transformar nossa escala de razão de variáveis em duas variáveis categóricas. A razão técnica é que a distribuição de crescimento de receita é altamente enviesada - existem muitos grupos com aumento modesto e poucos com aumento extremamente alto. A segunda razão é substantiva - acreditamos que as variáveis explicativas de prevenção de perda de receita sejam distintas das variáveis explicativas para se atingir um alto desempenho.

Como relata a Tabela 1, nossa primeira variável independente é a intercoesão: o número de dobras estruturais. Esperamos que a intercoesão diminua a probabilidade de diminuição da receita e aumente a probabilidade de alto crescimento de receita.

Nosso segundo pacote de variáveis independentes representa processos intracoesos. A primeira variável é o tamanho do grupo e o número de empresas do grupo. Similares à sociologia de números de Simmel, esperamos que grupos maiores tenham dinâmicas de receita diferentes daquelas de grupos menores, já que é menos provável que um grupo maior atinja um crescimento extraordinário. A segunda variável registra processo de homofilia baseados na homogeneidade do perfil da indústria. ${ }^{17}$ Medimos essa homogeneidade da indústria pela diferença numérica entre a primeira e segunda mais proeminentes categorias industrias do grupo. Se o grupo for totalmente constituído de uma única indústria, essa variável será igual a um. Caso haja duas categorias de indústria igualmente representadas, esta variável será igual a zero. Três outras variáveis se referem a processos de poder econômico e predomínio na estabilização ou desestabilização do grupo. O tamanho da maior empresa é medido em decis de capitalização, variando de 1 (menores empresas) a 10 (maiores empresas). Espera-se que esses poderosos atores econômicos possam manter o grupo unido (THYE, YOON e LAWLER, 2002). Para avaliar os efeitos do predomínio de economia relativa, registramos diferenças de tamanho como a diferença de tamanho decil entre as maiores e as segundas maiores empresa no grupo. O maior valor indica um ator claramente dominante no grupo, em termos de tamanho. Enquanto Thye e outros (2002) esperam que a igualdade de poder fomente a estabilidade do grupo, a formulação de Gould (2003) previa que a igualdade de poder levaria a conflitos e rompimento do grupo. A variável membros financeiros registra o número de empresas financeiras membros de um dado grupo. De acordo com Mizruchi e Stearns (1988), esperamos que os grupos com membros financeiros tenham um desempenho inferior.
Nosso terceiro conjunto de variáveis independentes representa processos extracoesos. Para cada grupo, registramos o ato de ser intermediado como o número de outros grupos para os quais o grupo é conectado por meio de um intermediário. Também registramos laços de ponte, o número de outros grupos que são alcançáveis com um laço direto originado no grupo em questão. Essas variáveis representam a intermediação como recentemente reformulada por Ronald Burt (2005). Enquanto Granovetter (1973) imagina que os grupos com laços de ponte teriam um melhor desempenho, também nos sintonizamos com a possibilidade de que o fato de ser intermediado possui implicações negativas no desempenho (FERNANDEZMATEO, 2007).

Entre os processos extracoesos, também consideramos o alcance do grupo a um campo político. Essa dimensão é saliente porque nosso caso envolve um profundo deslocamento econômico no contexto de uma transformação política simultânea (STARK e BRUSZT, 1998). Os grupos de negócios são vistos como veículos especialmente apropriados para a filiação política de tais mercados emergentes (KHANNA e RIVKIN, 2001). Incluímos três variáveis para abarcar os vários aspectos desses processos. Proporções politizadas registram a proporção de empresas de membros de grupos que tenham filiação a partidos por meio de laços pessoais. Um grupo exibe uma mistura política quando encontramos filiação a partidos em ambos os lados, direito e esquerdo. Laços com o partido do governo registram um grupo que tenha filiação política a um partido do atual governo.

As variáveis finais nesse grupo de processos extracoesos envolve laços com proprietários fora do grupo.$^{18} \mathrm{~A}$ proporção estatal registra a proporção de membros do grupo para o qual o Estado é um proprietário mais significativo. A proporção de propriedade estrangeira registra de forma similar a proporção de membros do grupo de propriedade estrangeira. Como variáveis de controle, incluímos anos assim como idade do grupo, definida como a média do número de anos que pares de grupos membros passaram juntos em grupos. Incluímos categorias específicas da indústria, um indicador de que o grupo foi recém-formado por empresas que não haviam pertencido a qualquer dos grupos dos anos anteriores, eficiência de mão de obra (medido como receitas sobre o número de funcionários) e eficiência de capital (medida como receitas sobre capitalização). Para corrigir a assimetria da distribuição dessas duas últimas variáveis, utilizaremos os logaritmos.

Ambos os modelos - o modelo do desempenho declinante e o modelo do alto desempenho - passam pelo 
Tabela 1 - Estatísticas descritivas

\begin{tabular}{|c|c|c|c|c|}
\hline VARIÁVEL INDEPENDENTE & MÉDIA & SD & MíN & MÁX \\
\hline Intercoesão & 2.707 & 2.746 & .000 & 19.000 \\
\hline Estabilidade do Grupo de $t$ para $t+1$ & .514 & .259 & .120 & 1.000 \\
\hline Estabilidade do Grupo de $t-1$ para1 & .438 & .282 & .000 & 1.000 \\
\hline Crescimento de receita de $t$ para $t+1$ & 1.587 & 3.945 & .170 & 63.190 \\
\hline Crescimento negativo de $t$ para $t+1$ & .544 & .499 & .000 & 1.000 \\
\hline Crescimento de quartil superior de $t$ para $t+1$ & .249 & .428 & .000 & 1.000 \\
\hline \multicolumn{5}{|l|}{ Processos intracoesos: } \\
\hline Tamanho do grupo & 4.661 & 1.168 & 4.000 & 11.000 \\
\hline Tamanho do capital da maior empresa & 9.355 & 1.241 & 1.000 & 10.000 \\
\hline Diferença de tamanho & 1.507 & 1.650 & .000 & 9.000 \\
\hline Membros financeiros & .722 & 1.101 & .000 & 8.000 \\
\hline Homogeneidade da indústria & .409 & .317 & .000 & 1.000 \\
\hline \multicolumn{5}{|l|}{ Processos extracoesos: } \\
\hline Intermediação & 19.242 & 10.870 & .000 & 44.000 \\
\hline Laços de ponte & 11.217 & 11.806 & .000 & 72.000 \\
\hline Proporção de estatais & .255 & .267 & .000 & 1.000 \\
\hline Proporção de propriedade estrangeira & .253 & .231 & .000 & 1.000 \\
\hline Proporção de laços políticos & .223 & .182 & .000 & .800 \\
\hline Combinação política & .260 & 439 & .000 & 1.000 \\
\hline Laços com o partido governista & .910 & 1.007 & .000 & 5.000 \\
\hline \multicolumn{5}{|l|}{ Controles: } \\
\hline Ano & 96.594 & 2.903 & 89.000 & 101.000 \\
\hline Idade do grupo & 2.817 & 1.820 & 1.000 & 11.000 \\
\hline Grupo recentemente formado & .113 & .317 & .000 & 1.000 \\
\hline Eficiência do mão de obra (log) & .700 & .530 & -.550 & 2.824 \\
\hline Eficiência do capital (log) & -2.636 & .652 & -4.513 & .447 \\
\hline Soma das receitas (log) & 4.067 & .701 & 2.400 & 5.701 \\
\hline \multicolumn{5}{|l|}{ Indústria: } \\
\hline Energia & .048 & .213 & .000 & 1.000 \\
\hline Mineração & .015 & .121 & .000 & 1.000 \\
\hline Química & .151 & .466 & .000 & 4.000 \\
\hline Metalúrgica & .061 & .253 & .000 & 2.000 \\
\hline Indústria pesada & .400 & .836 & .000 & 5.000 \\
\hline Indústria leve & .331 & .680 & .000 & 3.000 \\
\hline Madeira e têxteis & .140 & .396 & .000 & 3.000 \\
\hline Indústria de alimentos & .627 & 1.104 & .000 & 8.000 \\
\hline Construção & .258 & .878 & .000 & 6.000 \\
\hline Atacado & .421 & .655 & .000 & 4.000 \\
\hline Varejo & .367 & .659 & .000 & 4.000 \\
\hline Transporte & .102 & .319 & .000 & 2.000 \\
\hline Serviços & .650 & .869 & .000 & 4.000 \\
\hline
\end{tabular}


teste de Hosmer-Lemeshow de "fit" e pelo teste de laço de Pregibon de especificação do modelo. Fatores de aumento de tolerância e variância estavam dentro dos limites convencionais para todas as variáveis independentes, indicando que a multicolinearidade não deve ser uma preocupação. Para o teste de sensibilidade na definição do ponto de corte do alto desempenho nas 25 empresas top, executamos o modelo de alto desempenho com variáveis dependentes que representavam as empresas top $30 \%, 20 \%, 15 \%, 10 \%$ e $5 \%$ em crescimento de receita. Em todos esses modelos, o sinal e a significância do coeficiente de intercoesão foram os mesmos.

$\mathrm{Na}$ Tabela 2, vemos que intercoesão não previne contra o declínio da receita, mas é uma variável explicativa forte de alto crescimento. Deve-se ter em mente que, por definição, todos os grupos que examinamos na Tabela 2 são coesos.

Os grupos intercoesos apresentam performance superior a outros grupos, que carecem dessa vantagem ambígua mas recombinativa.

Voltando para as variáveis intracoesas, vemos que os grupos maiores tornam o declínio menos provável, sem contribuir para o crescimento. Para grupos de negócios, existe uma segurança nos números - grupos menores estão mais propensos ao declínio. A existência de um membro dominante com tamanho elevado faz com que seja mais difícil para um grupo atingir um crescimento elevado, provavelmente porque para grandes empresas uma alta taxa de crescimento signifique um aumento elevado no volume da receita. A homofilia é uma desvantagem. A homogeneidade da indústria aumenta a probabilidade de declínio e diminui a probabilidade de alto desempenho. Os grupos de composição mais heterogenea têm vantagens. Isso não se aplica, entretanto, a grupos que incluem membros de finanças. Os grupos com membros das finanças são significantemente mais propensos a enfrentar o declínio das receitas. Esse resultado pode não ser surpreendente para pesquisadores que estudam grupos de negócios: laços com bancos são normalmente associados a problemas financeiros e desempenho decrescente.

Olhando para os laços pessoais que atingem outros grupos de negócios, vemos que os efeitos no desempenho diminuem com o aumento da distância. Grupos com mais laços de dois passos para outros grupos (mediados mediante intermediadores) são ligeiramente menos propensos ao declínio, mas não mostram desvantagem no alto desempenho. Grupos com laços de maior alcance (nem mesmo a um passo de distância, mas estabelecidos por meio de dobras estruturais) se sobressaem a cliques, indiferentes a quão intensivamente ou extensivamente são incorporados. O número de laços de ponte para membros de outros grupos diminui a probabilidade de alto desempenho. Os laços de ponte - circuitos para a circulação de ideias - não contribuem para o sucesso do grupo. Isso contrasta fortemente com a contribuição positiva de intercoesão. Essa descoberta sublinha a importância da geração de ideias empresarial por meio da recombinação, ao contrário da dependência de ideias importadas de outras áreas da rede.

Atuar nos jogos de política partidária é um negócio perigoso. Enquanto contatos políticos não oferecem proteção contra o declínio, apenas a estratégia mais focada traz recompensas. Os grupos com mais laços políticos têm pouca chance de alcançar um alto crescimento. Os grupos que são altamente comprometidos com um partido colocam a confiança de seus negócios com parceiros em risco. Os grupos só podem tirar proveito de partidos políticos quando têm um laço com um partido do governo atual.

A intercoesão e a estabilidade de grupo operam como espelhos opostos. A estabilidade de grupo previne o declínio da receita dos grupos e não contribui para o crescimento da receita do quartil superior. A estabilidade na associação de grupo permite a reciprocidade, solidariedade e assistência mútua para agir como um tipo de tela de proteção, prevenindo assim perdas sérias de mercado no grupo. Mas a confiança e a melhoria da comunicação com o grupo não são ativos que estimulem altos níveis de crescimento: a estabilidade em si pode ser um fechamento com implicações conservadoras.

\section{INTERCOESÃO E ESTABILIDADE DO GRUPO}

Tendo analisado como a intercoesão é relacionada ao desempenho do grupo, vamo-nos voltar para questões de estabilidade do grupo. Para definir e medir a estabilidade do grupo, reportamo-nos ao artigo de Simmel "Persistência dos grupos sociais", onde ele defende que faz sentido falar de identidade do grupo, apesar do deslocamento da associação e da baixa institucionalização, caso haja alguma continuação de associação em estados contíguos:

Podemos dizer isto esquematicamente, como segue. Se a totalidade de indivíduos ou outras condições na vida do grupo é representada por $a, b, c, d$, e e mais tarde por $m$, $n, o, p, q$ então podemos todavia falar da persistência de idêntica individualidade se o desenvolvimento seguir o seguinte curso: $a, b, c, d, e-m, b, c, d, e-m, n, c, d, e$ $-m, n, o, d, e-m, n, o, p, e-m, n, o, p, q$. Neste caso, 
Tabela 2 - Predição de regressão logística de declínio da receita ou alto crescimento

\begin{tabular}{|c|c|c|}
\hline VARIÁVEL INDEPENDENTE & DECLÍNIO DA RECEITA (SIM=1) & $\begin{array}{c}\text { CRESCIMENTO DE RECEITA DO } \\
\text { QUARTIL SUPERIOR (SIM=1) }\end{array}$ \\
\hline Intercoesão & -.041 & $-.210 * * *$ \\
\hline \multicolumn{3}{|l|}{ Processos intercoesos: } \\
\hline Tamanho do grupo & $-.469 * * *$ & -.144 \\
\hline Tamanho do capital da maior empresa & -.046 & $-.588 * * *$ \\
\hline Diferença de tamanho & .061 & -.159 \\
\hline Membros financeiros & $.536 * * *$ & -.319 \\
\hline Homogeneidade da indústria & $.753^{*}$ & $-.948 * *$ \\
\hline \multicolumn{3}{|l|}{ Processos extracoesos: } \\
\hline Intermediação & $-.026 *$ & -.006 \\
\hline Laços de ponte & .019 & $-.040 * *$ \\
\hline Proporção de estatais & .385 & .425 \\
\hline Proporção de propriedade estrangeira & -.430 & -.355 \\
\hline Proporção politizada & .984 & $-2.904 * * *$ \\
\hline Associação política & -.046 & -.507 \\
\hline Laços com partido governista & -.109 & $.376^{*}$ \\
\hline \multicolumn{3}{|l|}{ Controles: } \\
\hline Estabilidade do Grupo de t para t-1 & $-1.685 * * *$ & .342 \\
\hline Ano & -.064 & -.037 \\
\hline Idade do Grupo & .033 & .162 \\
\hline Grupo recentemente formado & -.480 & -.049 \\
\hline Eficiência de mão de obra (log) & $-.980 * * *$ & $1.385^{* * *}$ \\
\hline Eficiência do capital (log) & -.189 & $.563 * *$ \\
\hline Soma das receitas (log) & $-.446 *$ & -.308 \\
\hline \multicolumn{3}{|l|}{ Indústria: } \\
\hline Energia & -.181 & -.884 \\
\hline Mineração & .741 & $1.880^{*}$ \\
\hline Química & .283 & .407 \\
\hline Metalúrgica & .212 & -.858 \\
\hline Indústria pesada & $.397^{*}$ & -.028 \\
\hline Indústria leve & $.613 * * *$ & -.274 \\
\hline Madeira e têxteis & $.524^{*}$ & -.039 \\
\hline Indústria de alimentos & $.367^{*}$ & .232 \\
\hline Construção & .102 & $.516 * *$ \\
\hline Atacado & $.616 * * *$ & -.313 \\
\hline Varejo & .304 & -.278 \\
\hline Transporte & .563 & -.505 \\
\hline Serviços & $.431 * *$ & .142 \\
\hline Constante & 9.850 & -7.637 \\
\hline$N$ & 430 & .430 \\
\hline$-2 L L$ & 520.588 & 400.756 \\
\hline$R^{2}$ & .192 & .245 \\
\hline$\%$ corretamente classificados & 67.1 & 77.9 \\
\hline$x^{2}(d f)$ & $65.022(33)$ & 76.679 (33) \\
\hline$P$-valor & .000 & .000 \\
\hline
\end{tabular}

Nota: $* P<10 \quad * * P<05 \quad * * * P<01$. 
cada estágio é diferenciado do estágio contíguo por apenas um membro, e a cada momento isto divide os mesmos elementos principais com seus momentos limítrofes. (SIMMEL, 1898, p. 670-71).

Trabalhamos com essa idéia em nossas análises de estabilidade do grupo. Para o primeiro ano de nosso conjunto de dados, usamos CPM para identificar cada um dos grupos coesos das empresas (p. ex. grupo coeso 1 é composto pelas empresas $a, b, c, d, e$; grupo coeso 2 é composto por $f, g, h, i, j$; a assim por diante). Para o segundo ano, identificamos os grupos coesos existentes naquele momento. (Seguindo o direcionamento de Simmel, podemos chamá-las de $f, b, c, d, e ; a, g, h, i, j ; v, w, x, y, z$; e assim por diante.) Como a formação de redes é, a princípio, lenta, e o número de grupos que aparecem bem no início pode ser apenas muito pequeno, modificamos o esquema de Simmel. Em vez de apenas seguir os primeiros grupos estabelecidos, identificamos todos os grupos que existiram de 1987 a 2001. Isto é, identificamos e registramos, para cada ano, todos os grupos coesos que existiram naquele ano. Ao observar a composição de todos os grupos em $t 1$ e aqueles em $t 2$, podemos registrar a proporção dos membros de qualquer grupo dado que se manteve coesivamente ligado - o que é nossa métrica de estabilidade - para todos os pares de anos.

Para medir a estabilidade dos grupos, registramos o fluxo de membros entre todos os grupos em anos adjacentes. Um grupo é completamente estável de um ano para o outro se todos os membros do grupo identificados no primeiro ano aparecerem juntos em um grupo no ano seguinte. No outro extremo, um grupo se desfaz se nenhum dos membros de $t 1$ aparecer em qualquer dos grupos de $t 2$. Entre estes extremos, um grupo em $t 1$ pode se dividir em segmentos de vários tamanhos que estejam presentes em grupos em $t 2$. Para medir tais níveis intermediários de estabilidade, registramos o tamanho médio dos trechos originados em $t 1$ que aparecer em grupos em $t 2$, dessa forma normalizando com relação ao tamanho do grupo original.

Para testar se a intercoesão possui seu próprio poder preditivo no contexto das explicações rivais, utilizamos um modelo de regressão multivariado, com a estabilidade do grupo como a variável dependente. As variáveis independentes são as mesmas que utilizamos em nossos modelos de desempenho de grupo.

Encontramos uma correlação negativa entre laços de intercoesão e estabilidade de grupo. A correlação média através de todos os anos é -0.55 , variando de -0.37 a -0.70. Esse modelo de regressão passou no teste de laço de Pregibon de especificação do modelo; fatores de tolerância e inflação de variância estavam dentro dos limites convencionais para todas as variáveis independentes: a multicolinearidade não deve ser uma preocupação. A Tabela 3 apresenta os resultados de nossos modelos de regressão predizendo a estabilidade do grupo.

Vemos que laços múltiplos de associação de intercoesão diminuem a estabilidade do grupo. Em outras palavras, grupos com mais dobras estruturais estão mais propensos à ruptura $\mathrm{e}$, quando o fazem, a romper-se em fragmentos menores. Esse resultado sugere que as dobras estruturais causam estresse no tecido da coesão. Os atores ambiguamente comprometidos produzem tensões de desestabilização dentro desses grupos.

Dos processos de intracoesão, apenas o tamanho do grupo é relevante: grupos maiores são menos estáveis. Das várias ligações extracoesas, apenas duas são relevantes para a estabilidade do grupo: intermediação e propriedade estatal. Como consequência marcante do processo de privatização, a estatização desestabiliza os grupos. Essa reorganização corrói a estabilidade dos grupos com empresas estatais.

O número de laços de intermediação para outros grupos é significantemente correlacionado com a diminuição de grupos coesos, uma conclusão que sugere que os intermediadores adversamente afetam as estruturas que exploram. Esse resultado está alinhado com a ideia de que o preço da intermediação é pago por aqueles conectados pelo intermediador (FERNANDEZ-MATEO, 2007). Além das perdas significativas, nossas conclusões mostram outra exterioridade da intermediação: a erosão de estruturas intermediadas. Essa erosão estrutural pode eventualmente diminuir as próprias oportunidades de intermediação.

Entre as variáveis de controle, não nos surpreendemos em concluir que a estabilidade do grupo no ano precedente está relacionada à estabilidade no ano atual. A estabilidade do grupo tem inércia. Também encontramos uma tendência positiva rumo à maior estabilidade do grupo decorrente do período pós-socialista - os grupos são mais estáveis nos anos subsequentes. Enquanto grupos recémformados, sem um histórico prévio de coesão, são estáveis no primeiro ano de sua existência, existe uma pequena desvantagem para os antigos grupos.

Os grupos com maior eficiência de mão de obra são mais estáveis, enquanto os grupos com maior eficiência de capital são menos estáveis. Um grupo com alto valor de capital e poucos funcionários é muito mais estável que um grupo com baixa capitalização e muitos funcionários Este último tipo de grupo foi o típico alvo da reorganização, que rompeu com a continuidade do grupo. Além 
disso, diversas categorias industriais são significantes e apresentam vários níveis de estabilidade do grupo quando comparadas com a categoria referência da agricultura.

Para resumir, concluímos que a dobra estrutural é de ruptura: grupos nos quais a associação não é exclusiva sofrem com a perda de estabilidade.

O contato de interpenetração entre grupos de negócios é destrutivo até além do que poderíamos esperar que acontecesse por acaso - os grupos parecem se romper com mais frequência quando um ou mais de seus membros assume múltiplas filiações.

\section{RECOMBINAÇÃO DAS GENEALOGIAS DE COESÃO}

A intercoesão representa um processo de ruptura generativa. Os grupos de negócios parecem enfrentar uma contradição fundamental: parecem forçados a escolher entre lutar tanto por estabilidade quanto por alto desempenho. Por um lado, a escolha da exclusividade pode render estabilidade com proteção concomitante de uma falha, mas não com a possibilidade de alto desempenho. Contudo, por outro lado, a escolha da não exclusividade de intercoesão abre possibilidades empresariais e a promessa de alto desempenho, embora sob o risco de desintegração. Isso deixa os grupos com duas possibilidades: ou eles permanecem exclusivos e estáveis, contentes com o seu modesto embora seguro desempenho, ou eles se empenham na ligação de intercoesão, possivelmente sobressaindo em relação à maioria dos outros grupos antes de se desintegrarem.

Entretanto, nossos dados indicam que existe uma terceira possibilidade que faz com que a ruptura criativa seja gerenciável: grupos conectados pela troca de membros operam como grandes coletividades que absorvem e, por isso, limitam a dispersão de membros de grupos desestabilizados, amenizando desse modo as rupturas causadas por dobras estruturais. Em vez de se tornar dispersa através da grande série de grupos em toda a economia, grupos se rompem para se reunir com outros próximos a eles e para reagrupar seus recursos em uma nova, mas familiar combinação. A instabilidade, desse modo, se torna recombinação de membros.

Nossas análises trabalharam até agora com dados que registram as alterações de um ponto no tempo, $t$, para o próximo, $t+1$. Nesta seção, vamos nos afastar da abordagem dinâmica para uma abordagem histórica ao seguir os padrões de fluxo de membros através de toda esta época. Nas seções anteriores, a unidade de análise foi um grupo em um determinado período, e estimamos a estabilidade e os efeitos no desempenho nos intervalos $t$ até $t+1$. Nesta seção, entretanto, nossa unidade de análise é uma coletividade de grupos ligada através do tempo, e seguimos toda a história destss coletividades através da estrutura histórica dos fluxos de associação.

De grupos nucleares, agora nos voltamos para estruturas de parentesco mais amplas de organizações empresariais. Os fluxos de membros traçam linhas entre grupos coesos. Embora um grupo possa não ter compartilhado nenhum membro com outro grupo no passado, ainda pode estar conectado a ele por meio de uma rede de ancestralidade. Nossa intuição é que grupos que partilham uma ancestralidade podem ficar próximos a outros, conectados por compartilhamento de intercoesão de membros e uma linha de descendência comum e repetidamente entrelaçada. Uma ancestralidade comum faz com que a formação de grupos seja mais fácil porque as rotinas de colaboração já são familiares. Essa familiaridade facilita a dobra estrutural: grupos que compartilham uma ancestralidade podem ser menos propensos a ter rotinas e culturas de colaboração radicalmente diferentes, que, desse modo, reduziriam os custos de coordenação na dobra estrutural.

Quando é que dois grupos são relacionados por uma ligação de descendência? De acordo com a ideia de Georg Simmel sobre a persistência de individualidade idêntica em grupos (Simmel, 1898), um grupo de cinco membros, $a, b, c, d, e$, é fortemente relacionado a um grupo subsequente com membros de $m, b, c, d, e$. Fica também claro que um grupo com $a, b, c, d$, e não tem relação com um grupo subsequente de $f, g, h, i, j$. Entre totalmente ligados e não ligados existem graus de força para um laço genealógico. Ao sermos fiel ao ímpeto fundacional da análise de rede social em nossa pesquisa, acreditamos que as propriedades de um grupo não são um resumo das propriedades de seus membros individuais. Em vez disso, eles emergem da estrutura de interação entre os membros. Essa idéia fundamental informa nossa definição de um laço genealógico. É duvidoso que dois grupos possam ser relacionados - no sentido de que existe continuidade no modo como o grupo opera e no propósito ao qual serve caso eles compartilhem apenas um membro. Como as qualidades do grupo se originam das interações por meio dos laços que o grupo contém, é necessário ao menos dois membros para estabelecer a continuidade entre o grupo antigo e novo grupo. A continuidade dos códigos de comunicação e colaboração depende de alguma continuidade de interação. Portanto, a continuidade na confiança e nas rotinas de reciprocidade e compartilhamento de recursos não pode ser transmitida por um único membro. Alinhada com esse discernimento, definimos o laço genealógico 
Tabela 3 - Preditivo de regressão linear de estabilidade do grupo

\begin{tabular}{|c|c|}
\hline VARIÁVEL INDEPENDENTE & ESTABILIDADE DO GRUPO \\
\hline Intercoesão & $-.018 * * *$ \\
\hline \multicolumn{2}{|l|}{ Processos intercoesos: } \\
\hline Tamanho do grupo & $-.028 * *$ \\
\hline Tamanho do capital da maior empresa & -.009 \\
\hline Diferença de tamanho & .010 \\
\hline Membros financeiros & .006 \\
\hline Homogeneidade da indústria & .029 \\
\hline \multicolumn{2}{|l|}{ Processos Extracoesos: } \\
\hline Intermediação & $-.008 * * *$ \\
\hline Laços de ponte & .001 \\
\hline Proporção de estatais & $-.078^{*}$ \\
\hline Proporção de propriedade estrangeira & .061 \\
\hline Proporção politizada & .021 \\
\hline Associação política & .004 \\
\hline Laços com partido governista & .003 \\
\hline \multicolumn{2}{|l|}{ Controles: } \\
\hline Estabilidade do Grupo de $t$-- 1 & $.204^{* * *}$ \\
\hline Ano & $.023^{* * *}$ \\
\hline Idade do Grupo & $-.013^{*}$ \\
\hline Grupo recentemente formado & $.127^{* * *}$ \\
\hline Eficiência de Mão-de-Obra (log) & $.037^{*}$ \\
\hline Eficiência do capital (log) & $-.033^{* *}$ \\
\hline Soma das receitas (log) & .004 \\
\hline \multicolumn{2}{|l|}{ Indústria: } \\
\hline Energia & -.041 \\
\hline Mineração & .086 \\
\hline Química & .032 \\
\hline Metalúrgica & -.003 \\
\hline Indústria pesada & $.029 * *$ \\
\hline Indústria leve & $.045^{* * *}$ \\
\hline Madeira e têxteis & $.068 * * *$ \\
\hline Indústria de alimentos & $.031 * *$ \\
\hline Construção & $.057 * * *$ \\
\hline Atacado & $.032 *$ \\
\hline Varejo & .019 \\
\hline Transporte & -.009 \\
\hline Serviços & -.001 \\
\hline Constante & $-1.613^{* * *}$ \\
\hline$N$ & 467 \\
\hline Ajustado $R^{2}$ & .472 \\
\hline$F(d f)$ & $13.671(33)$ \\
\hline$P$-valor & .000 \\
\hline
\end{tabular}


entre um grupo no tempo $t$ e outro grupo no tempo $t+1$ como o compartilhamento de, ao menos, dois membros.

A ideia de laços genealógicos aumenta a ideia da perseverança de grupos. Os laços genealógicos ligam grupos em pontos adjacentes do tempo como ancestrais ou descendentes. Uma genealogia de coesão representa um caminho evolucionário separado. A perseverança diz respeito ao comprimento da genealogia: um grupo que persiste por um longo período, mesmo se os membros são substituídos ao longo do caminho, é conectado com o passado por uma longa corrente de grupos. A perseverança diz respeito a apenas uma dimensão de uma genealogia seu comprimento. As genealogias também podem ter espessura - envolvendo grupos múltiplos em um determinado momento, todos conectados por uma ancestralidade compartilhada. Enquanto algumas genealogias são simplesmente correntes de perseverança linear, outras genealogias são mais complexas, com ramificações e reunificações. Nesse caso, a estrutura de laços genealógicos é mais complexamente organizada: membros que deixam o grupo terão uma forte tendência a modificar um grupo com outros membros com a mesma genealogia.

A Figura 2 representa um exemplo de uma genealogia entrelaçada. Em 1995, essa genealogia inicia com um grupo que possui três dobras estruturais com grupos fora da genealogia. No ano seguinte, esse grupo se divide em dois grupos com sobreposição de membros. Em seguida, os dois grupos não estão estáveis, mas não se dissolvem inteiramente; a genealogia é mantida.

A genealogia apresentada nesse exemplo mostra algumas das propriedades estruturais distintas. As gerações futuras de grupos - por exemplo, os dois grupos em 1999 compartilham uma ancestralidade de coesão que remete a 1995 (no contexto pós-socialista, uma época inteira). Além de simplesmente compartilhar o legado das rotinas do grupo de 1995, suas linhas de ascendência foram repetidamente entrelaçadas de tal forma que podem, de fato, traçar a genealogia para quase todos os grupos precedentes. Este entrelaçamento de genealogia contém grupos que são ligados por intercoesão em cada período. Estes grupos não são estáveis: quase todos eles se dividem de um ano para o outro. Embora a associação de grupos individuais seja volátil, a associação genealógica é estável. Isto não é para dizer que a estabilidade significa imobilidade: em qualquer período de tempo, grupos dentro da genealogia são recombinados.

Propomos que a existência de genealogias entrelaçadas segue de um princípio de organização que retém membros de grupos desestabilizados que são próximos uns dos outros. Mas também podem se formar genealogias diretas ou entrelaçadas - quando se criam laços aleato- riamente, quando uma empresa em um grupo coeso tem igual probabilidade de ser membro de qualquer um dos grupos no próximo ano. Para testar a aglomeração sob condições aleatórias, computamos os tamanhos observados de distribuição de genealogias com o tamanho com que a distribuição é simulada em um conjunto de dados. Se emergem genealogias similares em tamanho com a mesma frequência em simulações aleatórias, podemos rejeitar nossa hipótese de que as genealogias são resultado da organização de negócios.

Figura 2 - Um exemplo de uma genealogia entrelaçada. Os círculos representam os grupos, com tamanho proporcional à associação. Setas sólidas representam a continuidade dos membros de ao menos duas empresas; uma linha tracejada indica a dobra estrutural

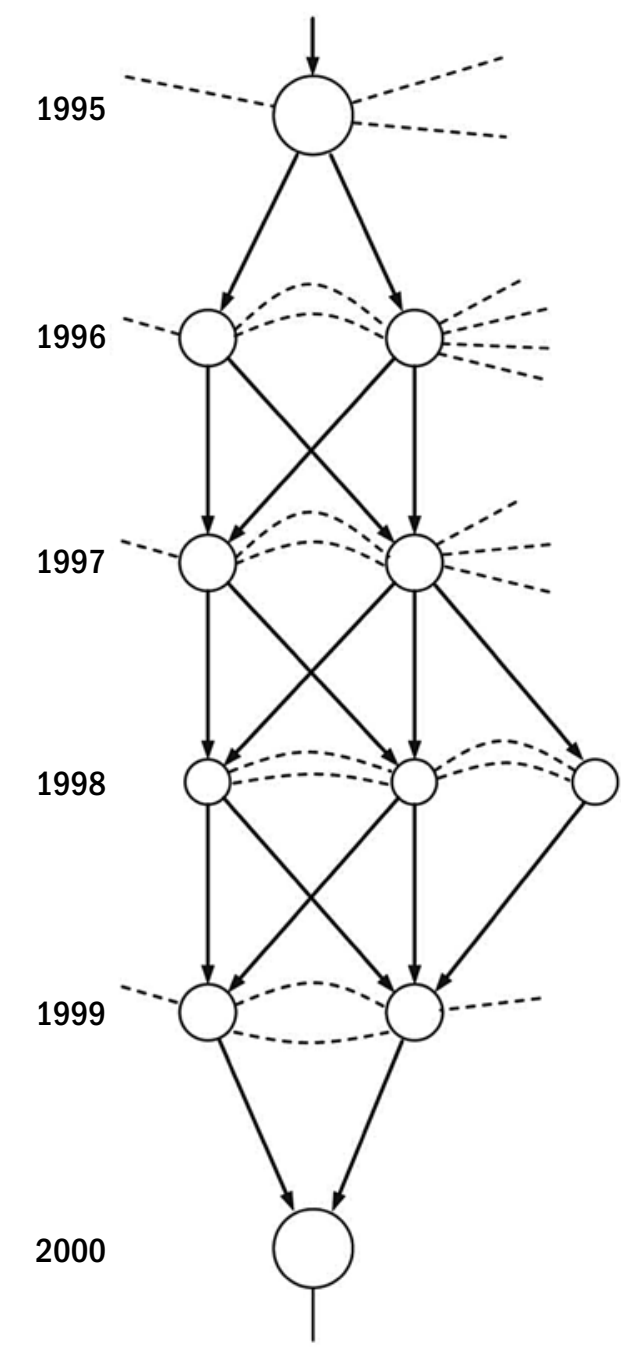


Fizemos simulações para testar a aleatoriedade como uma explicação para a existência das genealogias. Em nossas simulações, fixamos a distribuição de graus de entradas e saídas de laços genealógicos em cada ano, enquanto randomizamos as conexões particulares. Em tais conjuntos de dados simulados, a divisão ocorre com a mesma probabilidade em cada ano, assim como o faz com o conjunto de dados observados naquele dado ano, mas os membros que se separam são aleatoriamente atribuídos a seus grupos de destino. O mesmo acontece com as fusões - as fusões ocorrem com a mesma frequência que no conjunto de dados observado, mas as fusões em particular são geradas aleatoriamente. Cada simulação fornece uma completa genealogia de conjunto de dados de 1987 a 2001. Geramos 1.000 desses conjuntos de dados para estimar a distribuição de tamanhos de genealogias quando membros migram aleatoriamente para outros grupos.

Nossas conclusões indicam que é muito difícil que as genealogias observadas sejam um resultado de laços aleatoriamente conectados. Como uma ilustração, a Figura 3 mostra as 10 maiores genealogias em um conjunto de dados representativamente simulado (onde a aglomeração de estatísticas foram as mais próximas do significado

Figura 3 - As 10 maiores genealogias de coesão simuladas de todas as simulações). A Figura 4 mostra as 10 maiores genealogias no conjunto de dados observado. A mais impressionante diferença entre as genealogias simuladas e observadas é que a maior genealogia nos dados simulados é muito maior que a segunda maior. Nossa primeira medição de tamanho de distribuição de genealogia é o tamanho relativo da maior genealogia para a segunda maior. Em nossas simulações, a maior genealogia tem, em média, 32 vezes o tamanho da segunda maior. Em nosso conjunto de dados observado, a maior delas é cerca de duas vezes maior que a segunda. Apenas em oito das mil simulações essa razão foi menor ou igual a dois.

Outra medida de agrupamento é o tamanho relativo do maior componente do tamanho da genealogia do conjunto de dados completo. Nos dados observados, o maior componente englobava apenas $14 \%$ do conjunto de dados total. Em mil dos conjuntos de dados simulados, o maior componente ocupava, em média, $69 \%$ de um dado conjunto de dados. Em apenas quatro das mil simulações, o maior componente era tão pequeno quanto o maior componente dos conjuntos de dados observados, a saber, $14 \%$. As genealogias não acontecem por acidente.

Também descobrimos que as genealogias interligadas contêm densos laços de intercoesão entre os grupos nele
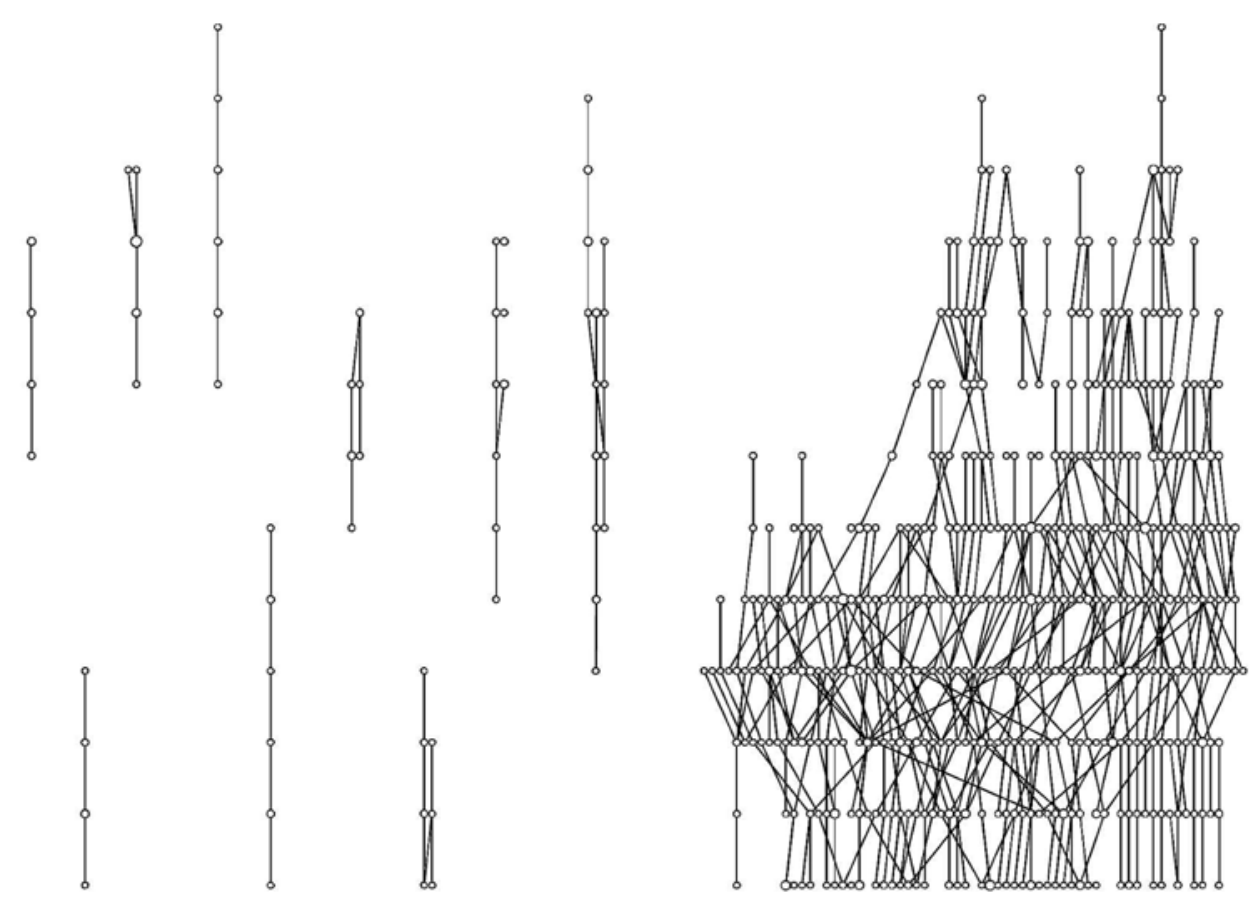
contidos. Olhando para todos os pares de grupos onde a intercoesão é possível (grupos que coexistiram no mesmo ano), descobrimos que a densidade dos laços de intercoesão é muito maior para aqueles pares de grupos que estão dentro da mesma genealogia. A densidade dentro de genealogias entrelaçadas é de $49 \%$, isto é, quase metade dos pares dentro de tais genealogias é conectada por intercoesão. Por exemplo, em uma genealogia entrelaçada com quatro grupos, três dos seis pares possíveis seriam conectados - o suficiente para fazer da genealogia um componente conectado. A densidade para pares de grupos que não compartilham uma genealogia é de apenas 3\%. Como comparação, computamos os mesmos índices de densidade para a genealogia típica dos conjuntos de dados genealógicos simulados na Fgura 3. Nesse conjunto de dados simulado, a densidade de intercoesão dentro das genealogias é de apenas 5\% - em contraste com os 49\% nos dados observados.

$\mathrm{Na}$ Figura 4 também destacamos uma das genealogias entrelaçadas. Esse é o grupo da indústria do aço, "Metais Pesados", com o qual Stark (1996) conduziu uma pesquisa etnográfica durante o início do período pós-socialista. Esse grupo é uma ilustração interessante de nosso método de sequência social para a identificação de grupos de negócios através dos tempos. Metal Pesado é relativa- mente um dos poucos grupos de negócios que existem como uma entidade nomeada na paisagem da economia húngara. Na verdade, o nome de cada empresa indica que ela pertence a esse grupo de negócios. Das 18 empresas designadas como Metal Pesado em nosso conjunto de dados, 17 delas são classificadas por nosso método em sua genealogia entrelaçada. A história desse grupo de negócios, que teve início em 1992 e foi estudada por Stark em 1993-1994, mostra que a experimentação organizacional não teve restrições no início do período pós-socialista. Por meio de repetidas recombinações de associações de subgrupos, a coerência do Metal Pesado é mantida em meio às mudanças de propriedade e influxo de investimento direto estrangeiro, assim como por meio de mudanças no governo e troca de afiliações partidárias.

No contexto de grupo de negócios, um foco em linhas de coesão destaca o fato de que o princípio de organização é mais complexo do que meramente trazer empresas para um contato de coesão mais próximo. A organização de grupos de negócios também envolve a separação estratégica - mantendo separados os conjuntos de membros enquanto, ao mesmo tempo, mantém a coerência histórica. O desdobramento histórico da organização de grupos de negócios deixa seus traços como genealogias de coesão. As genealogias destacam um importante balanço entre duas

Figura 4 - As 10 maiores genealogias de coesão observadas

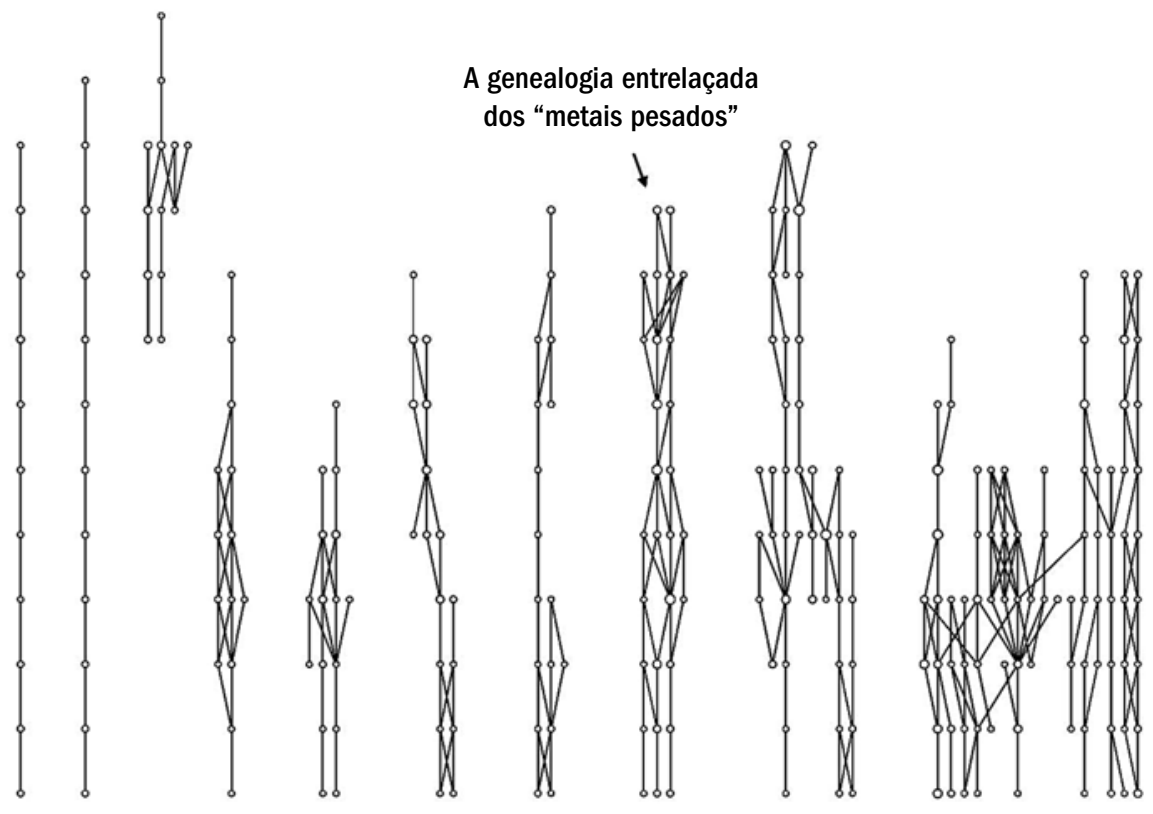


forças. Enquanto o atrito da intercoesão repetidamente desmonta grupos, a genealogia compartilhada mantém seus membros dentro de uma esfera de trocas na qual os recursos dos membros são redistribuídos e recombinados. A intercoesão previne grupos contra o congelamento causado pela proteção defensiva da exclusividade, enquanto a genealogia previne grupos contra a explosão que pode dissipar os recursos acumulados.

\section{CONCLUSÃO}

A análise de redes sociais produziu uma rica gama de conceitos analíticos e poderosos métodos de estudo de características estruturais da ação econômica. Do conceito de Granovetter (1985) sobre ação inserida (embedded action), por exemplo, a sociologia desenvolveu uma abordagem sistemática para prever o comportamento econômico da estrutura de laços sociais. Os métodos de análise de redes sociais concebidas para identificar cliques, centros, clãs e outros grupos coesos forneceram operacionalizações poderosas para o conceito de inserção (embeddedness). Junto ao conceito de White sobre a equivalência estrutural veio a ideia de que atores devem se comportar de forma similar não porque são interligados, mas porque compartilham uma localização comum dentro de padrões mais gerais de laços. Utilizando o método de modelagem em bloco, White e seus colegas afastaram a atenção dos estudiosos do entendimento convencional sobre redes como "quem conhece quem?" para concluir que laços ausentes são igualmente importantes (WHITE, BOORMAN e BREIGER 1976). Ao longo dessa linha de pensamento, a análise de redes aumentou sua atenção para a inclusão de modelos nos buracos ou espaços da estrutura social. A ideia de laços fracos de Granovetter (1973) e o conceito de Burt (1992) de buracos estruturais desenvolveram essas idéias em análises sistemáticas de oportunidades de intermediação, acesso a informação e restrição estrutural. Recentemente, o conceito de Watts sobre pequenos mundos destacou a união da importância da ligação de coesão e laços de longa distância que atingem os vazios estruturais para o entendimento de fluxos de informação (WATTS 1999) e a robustez na resposta à crise (DODDS, WATTS e SABEL 2003).

Comum a todos esses esforços é a atenção dada à topologia das redes. Cada um dos conceitos - inserção (embedding), equivalência estrutural, laços fracos, buracos estruturais, pequenos mundos - se refere à específica tipologia de características de redes. Nosso trabalho contribui para esses esforços por meio do desenvolvimento do conceito de intercoesão e, então, pela identificação de suas características topológicas correspondentes, onde estruturas coesas de grupo se dobram-se umas sobre as outras. Ao mesmo tempo que mantemos a idéia de que propriedades estruturais são formadas pela presença e ausência de laços (a ausência de laços entre grupos, característica exclusiva da dobra estrutural, é primordial na definição de grupos como unidades distintas), apontamos para uma posição distinta onde estruturas de redes de coesão se sobrepõem e se interpenetram. Enquanto o conceito de Burt sobre buraco estrutural identifica um local de redes propício para a intermediação, nosso conceito de dobra estrutural identifica um local-chave de rede na atividade empresarial da recombinação.

Desse modo, em contraste com a imagem de Burt de uma estrutura que liga ou se extende por meio de um buraco, consideramos um local onde as estruturas se dobram juntas umas sobre as outras. Por trás dessa diferença de imagens, existe ainda uma diferença na conceitualização do que acontece dentro das redes. No caso de intermediação, as redes sociais são canais, um meio de transporte, um sistema de comunicação. Como circuitos elétricos, eles conduzem: os homólogos dos elétrons são, acima de tudo, pedaços de informações, mas também rumores e recursos que fluem através dos circuitos da rede. De acordo com esta ideia, as posições das redes são importantes na medida em que são insubstituíveis na manutenção de fluxos entre os maiores segmentos da rede.

Se o fluxo ou movimento das informações é a atividade crítica que ocorre através do conduíte ou no ponto de contato através do buraco estrutural, a geração de conhecimento através da recombinação é que é a atividade crítica entre os grupos de intercoesão. Correspondentemente, a metáfora da eletricidade é substituída por outras mais adequadas de química molecular. Em vez de ver as redes como a fiação por meio da qual os elétrons de informação fluem, deveríamos pensar nas redes como um tipo de ligação molecular na qual os laços conectam nós em grandes agrupamentos que representam uma nova qualidade molecular e não meramente uma extensão de circuitos para outros átomos da rede. A intercoesão estabelece fortes conexões entre as moléculas de rede para gerar um material mais complexo de alianças criativas. Nessa visão de uma rede social, os fluxos são secundários. A informação pode ser codificada, mas o conhecimento é uma prática ligada aos arranjos sociotécnicos particulares. Quanto mais inovador o conhecimento, menos propenso de ser completamente codificado e facilmente transmitido à parte destes arranjos. Através da sobreposição de laços fortes que ligam mais de um grupo, as dobras estruturais 
oferecem oportunidades para a mistura ou recombinação de práticas de conhecimento.

A intercoesão é o processo através do qual novas ideias são geradas, ao contrário de um local onde fluxos de informação apenas sofrem pedágio.

Enquanto as análises de redes sociais nos deram uma plenitude de conceitos para o estudo de propriedades estruturais de redes, o campo produziu muito menos conceitos para a análise de características temporais ou históricas de redes - apesar do fato de que Georg Simmel, uma das figuras fundadoras da análise de redes, abordou a dimensão temporal em uma das edições do American Journal of Sociology. Em seu ensaio "Persistência de Grupos Sociais", Simmel (1898) ponderou se faria sentifo falar de identidade do grupo em casos de troca de associações e baixa institucionalização.

O desafio de Simmel persiste. Mais de um século depois, a análise de redes sociais enfrenta um problema teórico e metodológico fundamental ao mover-se de um conceito transversal para um conceito dinâmico e histórico de grupo coeso. Como podemos identificar um grupo através do tempo em termos de rede? Um grupo pode mudar sua composição e ainda preservar sua identidade? O problema é simples onde grupos são nomeados, catalogados e registrados, por exemplo, na Suprema Corte, o Youngstown Garden Club, o Mitsubishi keiretsu, ou o Samsung Group. Apesar das trocas de associação através dos séculos, o departamento de sociologia da Universidade de Chicago permanece assim por conta da continuidade institucional. Mas as redes sociais que formam os grupos corporativos húngaros, assim como muitos dos grupos estudados por análises de rede, não possuem tal institucionalização. Como estudamos a evolução do grupo onde não podem ser nomeados?

Nosso trabalho aborda este desafio diretamente. A partir das contribuições de Simmel, elaboramos um conceito de identidade histórica de grupo baseada na continuidade da associação em estados contíguos. Tal continuidade da associação não precisa ser absoluta, mas deve haver alguma sobreposição de (ao menos dois) membros dos grupos para legar de um ano para o outro. A operação resultante produz outra nova forma de representação da topologia da rede - uma genealogia de coesão - na qual a estrutura pode ser exibida e analisada através da dimensão temporal. Como vimos, algumas genealogias levam a forma de uma linha única, sem ramificações. Mas outras - genealogias entrelaçadas - são construídas através da divisão e reunificação em um padrão em andamento de entrelaçamento. No desenvolvimento de uma rede de análises históricas, combinamos ênfase na estrutura (características de rede de análises sociais) com ênfase nos processos temporais (características de sociologia histórica). Os resultados fazem com que seja possível a identificação de maiores coletividades que ao contrário seriam invisíveis em uma fotografia estática. Essa habilidade de reconhecimento de padrões em dados de redes históricas terá uma maior aplicabilidade para fenômenos com dois níveis de institucionalização assim como movimentos sociais, indústrias emergentes, ou novas escolas de pensamento científico ou literário.

Deste modo, como uma contraparte direta da topografia de intercoesão junto à dimensão sincrônica, identificamos genealogias entrelaçadas através da dimensão diacrônica. De uma forma não similar à dobra estrutural - onde encontramos a recombinação ocorrendo em pontos de diversidade dentro de familiaridade - também concluímos, junto à dimensão histórica, que grupos se formam e se reformam junto às linhas em padrões de coerência, se separando para englobar uma maior diversidade e se reunindo para se beneficiar da familiaridade. Seja na sequencia de intercoesão ou junto à dimensão histórica de genealogias entrelaçadas, o esforço recombinante de inovação exige evitar-se tanto a familiaridade quanto a diversidade.

\section{APÊNDICE}

\section{0 método de percolação de cliques}

O método de percolação de cliques opera na adjacência dos cliques; k-cliques são adjacentes se compartilharem vértices $k-1$. Um clique de quatro é adjacente a outro clique de quatro se eles compartilharem três membros. Das adjacências, um pode reunir uma corrente de cliques, percorrendo as adjacências dos cliques. A união de todos os $\mathrm{k}$-cliques em tal corrente forma um aglomerado percolado de k-cliques se nenhum outro k-clique puder ser adicionado. Essa região contígua e altamente coesa da rede é um grupo coeso, dentro do qual um k-clique pode percolar, ou prosseguir, sempre substituindo um dos nós k. Utilizando um valor k de quatro, como fazemos neste estudo, se produz grupos coesos onde todos os membros possuem laços com ao menos três outros membros do grupo.

A Figura Al ilustra a lógica do método CPM na identificação de um pequeno grupo coeso. Iniciamos pela identificação de um 4-clique, e na etapa 1, este 4-clique prossegue por meio d a substituição de um nó. Na etapa 2, o 4-clique novamente prossegue, e na etapa final, etapa 3 , o grupo é identificado, na medida em que não há mais como manter o 4-clique. 
O parâmetro k do método CPM é ajustável. A escolha de um k menor resulta em uma distribuição mais irregular de tamanho de grupos. Um valor $\mathrm{k}$ de um é de pouca utilidade; se considerarmos a percolação dos subgráficos completos de um nó, isso significa que toda a rede é um grupo. Nesse valor extremo, o tamanho da distribuição dos grupos é a mais extrema - existe apenas um grupo que en- globa toda a rede. Um $\mathrm{k}$ de dois significa que consideramos a percolação de subgráficos completos de dois nós, equivalentes na consideração da percolação de díades. Nesse caso, grupos coesos são os componentes desconectados do gráfico. O tamanho da distribuição dos componentes é bastante enviesado, porque um componente gigante, que contém uma proporção enorme de nós, é uma caracterís-

Figura A1 - llustração da lógica do algoritmo CPM

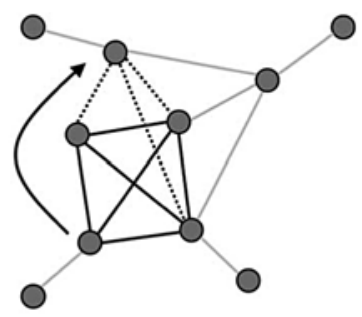

Etapa 1

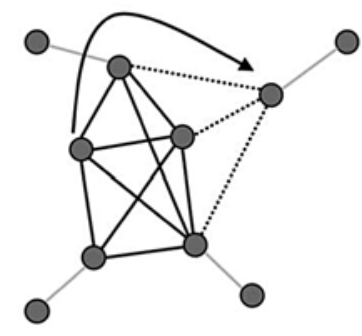

Etapa 2

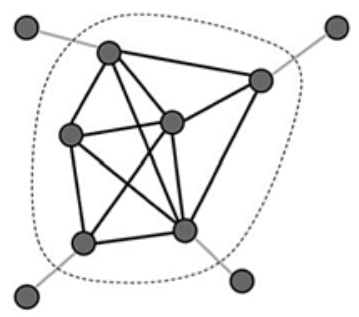

Etapa 3

Tabela A1 - Distribuição do tamanho do grupo e cobertura do nó com o método CPM em vários valores $\mathrm{k}$

\begin{tabular}{|c|c|c|c|c|c|c|c|c|}
\hline & \multicolumn{2}{|c|}{$K=2$} & \multicolumn{2}{|c|}{$K=3$} & \multicolumn{2}{|c|}{$K=4$} & \multicolumn{2}{|c|}{$K=5$} \\
\hline ANO & $\begin{array}{l}\text { MAIOR } \\
\text { GRUPO a }\end{array}$ & $\begin{array}{c}\text { COBERTURA } \\
\text { DO NÓ b }\end{array}$ & $\begin{array}{l}\text { MAIOR } \\
\text { GRUPO }^{\text {a }}\end{array}$ & $\begin{array}{c}\text { COBERTURA } \\
\text { DO NÓ b }\end{array}$ & $\begin{array}{l}\text { MAIOR } \\
\text { GRUPO a }^{\text {a }}\end{array}$ & $\begin{array}{c}\text { COBERTURA } \\
\text { DO NÓ }\end{array}$ & $\begin{array}{l}\text { MAIOR } \\
\text { GRUPO a }^{\text {a }}\end{array}$ & $\begin{array}{c}\text { COBERTURA } \\
\text { DO NÓ b }\end{array}$ \\
\hline 1989 & 18.40 & 48.76 & 1.25 & 20.85 & 1.00 & 5.65 & & .00 \\
\hline 1990 & 33.80 & 45.23 & 1.20 & 25.38 & 1.25 & 5.53 & 1.00 & .95 \\
\hline 1991 & 53.00 & 57.02 & 4.73 & 32.20 & 1.50 & 11.26 & 1.20 & 5.57 \\
\hline 1992 & 53.30 & 61.72 & 4.85 & 38.83 & 1.57 & 14.93 & 1.17 & 7.05 \\
\hline 1993 & 140.60 & 62.92 & 1.27 & 42.98 & 1.17 & 15.86 & 1.17 & 8.01 \\
\hline 1994 & 106.86 & 63.13 & 1.47 & 45.48 & 1.13 & 16.44 & 1.29 & 7.26 \\
\hline 1995 & 106.86 & 61.32 & 1.41 & 42.81 & 1.13 & 17.48 & 1.14 & 6.81 \\
\hline 1996 & 69.18 & 60.12 & 5.00 & 43.38 & 1.10 & 21.36 & 1.17 & 9.69 \\
\hline 1997 & 130.83 & 59.56 & 4.37 & 40.18 & 1.10 & 22.66 & 1.17 & 8.47 \\
\hline 1998 & 131.67 & 58.41 & 4.33 & 40.97 & 1.38 & 22.08 & 1.17 & 7.28 \\
\hline 1999 & 132.17 & 56.71 & 3.64 & 39.35 & 1.14 & 18.72 & 1.14 & 4.62 \\
\hline 2000 & 109.14 & 55.11 & 3.41 & 37.65 & 1.14 & 15.75 & 1.14 & 5.60 \\
\hline 2001 & 124.67 & 54.06 & 2.11 & 37.05 & 1.13 & 14.89 & 1.29 & 5.02 \\
\hline Média & 93.11 & & 3.00 & & 1.21 & & 1.17 & \\
\hline Mín & 18.40 & & 1.20 & & 1.00 & & 1.00 & \\
\hline Máx & 140.60 & 5.00 & & 1.57 & & 1.29 & & \\
\hline
\end{tabular}

Nota: a. Células indicam o tamanho relativo do maior grupo em comparação com o segundo maior grupo.

b. Células contêm porcentagens de todas as empresas no conjunto de dados de um determinado ano. 
tica comum das redes. Ao aumentar o valor de $k$ para três significa considerar triângulos (tríades completas), como o subgráfico percolado. Os grupos, neste caso, são constituídos por triângulos que compartilham ao menos dois nós. A distribuição dos tamanhos dos grupos é mais regular, embora em redes mais densas o maior agrupamento obtido por uma percolação de triângulos pode ainda ser muito maior que a segunda em tamanho. Mudando para um k de quatro, é ainda mais restritivo, já que os grupos precisam ser densos o suficiente para permitir a percolação de subgráficos completos de quatro. Nesse caso, a distribuição dos tamanhos dos grupos é mais regular, e pode não haver um grupo que seja claramente o maior.

Decidimos usar o valor $\mathrm{k}$ de quatro na identificação dos agrupamentos de percolação de cliques. A maioria das aplicações do método CPM concluiu que existe uma transição de percolação k-valor de quatro e três. Enquanto um $k$ de quatro produz grupos que têm aproximadamente o mesmo tamanho, um $\mathrm{k}$ de três produz uma distribuição altamente enviesada de tamanhos de grupos (Palla e outros, 2005). Nossos dados confirmam esta conclusão: com um $k$ de três, o maior grupo é, em média, três vezes maior que o segundo maior grupo, enquanto em alguns anos é cinco vezes maior. Com um $\mathrm{k}$ de quatro, o maior grupo é, em média, 1,21 vezes maior que o segundo maior, e a distância máxima é 1,57 (veja a Tabela A1). Desse modo, decidimos utilizar $k=4$ para identificar grupos coesos com o método CPM.

\section{NOTAS}

1. A pesquisa para este artigo teve apoio de uma doação da National Science Foundation, $\mathrm{N}^{\circ}$. 0616802. Alternamos a ordem dos nomes dos autores por meio de uma série de trabalhos produzidos pelo nosso mais amplo projeto de análises históricas de rede. Por seus comentários, críticas e sugestões, agradecemos a Peter Bearman, Laszlo Bruszt, Monique Girard, David Lazer, David I. Levine, Anna Mitschele, Guido Moellering, John Padgett, Roger Schoenman, Tamás Vicsek e Douglas R. White. Nossos agradecimentos ao Institute of Advanced Study da Universidade de Durham, na Grã-Bretanha, e ao American Journal of Sociology. E ao Instituto Max Planck para Estudo das Sociedades, em Colônia, na Alemanha, por hospedar Stark como um querido visitante enquanto o manuscrito era preparado. Correspondência direta a Balazs Vedres, Central European University, Zrinyi ulitsa 14, 1051, Budapeste, Hungria.E-mail: vedresb@ceu.hu ou dcs36@columbia.edu.

2. Nosso estudo contribui para a análise de redes históricas utilizando grandes conjuntos de dados por períodos de tempo relativamente longos. Padgett e McLean (2006), por exemplo, desenvolveram uma abordagem de rede múltipla a fim de estudar a criação do formato bancário por 80 anos na Florença renascentista. Powell e outros (2005) aplicam uma abordagem de rede dinâmica para entender a emergência da biotecnologia, seguindo os laços entre mais de 2.000 empresas por um período de mais de 12 anos. Uzzi e Spiro (2005) inspecionam propriedades de redes de coesão e conectividade entre uma população de 2.092 pessoas que trabalharam em 474 musicais da Broadway entre 1945 e 1989 (veja também WUCHTY, JONES e UZZI, 2007).

3. Aglomerados de algoritmos utilizados por analistas de rede tipicamente analisam estruturas coesas em comunidades separadas resultando em um ponto cego para associação a grupos múltiplos. Em seu artigo sobre conceito de grupo social, por exemplo, Linton Freeman afirma que as sobreposições apenas acontecem entre grupos de diferentes contextos sociais (assim como trabalho, parentesco e amizades), e uma vez que o contexto é esclarecido, há pouca, se não nenhuma, sobreposição (FREEMAN, 1992). Questionamos que a divisão de redes sociais em grupos disjuntivos sociais é artificial, impulsionado mais por limitações de visão metodológica do que sociológica. Encontros em conjunto em departamentos acadêmicos constituem uma sobreposição de dois ou mais grupos departamentais. Famílias nucleares se formam como a sobreposição dos grupos de parentesco maternal e paternal. A participação em mais de um grupo de amigos não é rara. Uma perspectiva mais realista, assim, admite que grupos sociais podem ser de coesão e sobrepostos.

4. Um recente trabalho sobre a metodologia da rede social reconhece que as atuais estruturas de rede podem ser compostas por grupos coesos sobrepostos (MOODY e WHITE, 2003). Nossa contribuição analítica é o reconhecimento de que, se grupos coesos podem se sobrepor, existe uma distinta posição estrutural em sua interseção. Isto é, a partir de um resíduo metodológico, apontamos para a localização da interseção como um objeto sociológico digno de reflexão.

5. Extraímos a definição de Schumpeter de empreendedorismo como sendo "a execução de novas combinações." Como via de regra, as novas combinações devem extrair os meios necessários de produção a partir de antigas combinações. "[...] o desenvolvimento consiste primariamente do emprego de recursos existentes de forma diferente, fazendo deles novas coisas" (SCHUMPETER, 1934, p. 68). Para uma declaração neoschumpeteriana no campo dos modelos de crescimento econômico, veja Weitzman (1998).

6. Como inovação, nesse ponto de vista, envolve a reunião de tradições incompatíveis, não devemos esperar que os processos sejam harmoniosos. Como retrospectiva, é fácil ver que o jeans surrado é uma recombinação das roupas dos operários e da tecnologia de lavagem. Se podemos dizer que, "claro!", os telefones celulares são o casamento do rádio e do telefone, é apenas porque, como mostram Lester e Piore, as respectivas comunidades trabalharam desde o ponto inicial de suas diferenças.

7. Pontes podem ter um impacto notável em grupos coesos apenas em trajetórias de dois passos. Membros de grupos intermediados são, na melhor das hipóteses, amigos de amigos. A força do impacto entre os grupos é limitada pelos laços fracos que estão entre eles. Enquanto os atores do buraco estrutural ocupam uma posição de intermediação nesse hiato $e$ exercem o papel de "pedágio" nesses fluxos, os atores de intercoesão ocupam uma posição empresarial na sobreposição e recombinam recursos.

8. Ao examinar como diferentes domínios de conhecimento são reunidos para formar algo novo e original, Lester e Priore dizem que "a ambiguidade é o recurso crítico de onde as novas ideias emergem... O telefone celular emergiu no espaço criado pela ambiguidade sobre se o produto era um rádio ou um telefone; ao jogar com esta ambiguidade, o aparelho se tornou algo diferente de ambos, rádio e telefone" (LESTER e PIORE 
2004, p. 54). Lester e Piore, posteriormente, observam que as tecnologias do rádio e do telefone requerem uma tradição comercial e de engenharia diferente, com o segmento da indústria de rádio na qual a tecnologia do celular derivou, sendo particularmente distinta, e baseada em um rádio bidirecional montado em carros de polícia e viaturas de bombeiros. "As diferenças culturais entre a engenharia de rádio e a de telefone estavam profundamente enraizadas" (LESTER e PIORE 2004, p. 17).

9. Declarações de fundação no campo de análise de redes concentraramse nos problemas de duração e temporalidade. Moreno e Jennings (1937, p. 371), por exemplo, definiram coesão como "as forças que mantêm um indivíduo dentro dos grupos nos quais estão". Na metade do século, o estudo de Festinger, Schachter e Back (1950, p. 164) sobre pressões sociais em grupos informais abordou "a totalidade do campo de forças que atua em membros para permanecer no grupo" (veja MCPHERSON, SMITH-LOVIN [2002] e FRIEDKIN [2004] para discussão). Nessa ênfase, eles ressoam Simmel, cuja publicação em uma antiga edição do American Journal of Sociology foi intitulada "A persistência dos grupos sociais" (SIMMEL 1898).

10. Ao analisar as dinâmicas dos grupos de negócios de interseção, seguimos as ideias teóricas de estrutura e agência mais proeminentemente formuladas por William Sewell (1992). Argumentos sociológicos que envolvem estruturas são tipicamente destinados a explicar estabilidade, fechamento e reprodução. Para explicar a mudança social, a abertura de novas possibilidades, e rupturas em reprodução social, os sociólogos procuram evidências de choques externos, forças externas. Sewell demonstra o conceito de estrutura que possibilita a mudança originada internamente. Ele propõe que a interseção de estruturas, grupos sociais em nosso caso, ajuda a explicar a mudança sem referência de impactos externos.

11. Dados de detentores de cargos políticos e governamentais foram coletados do Tribunal Regional Eleitoral (que mantém registros de todos os funcionários de cargos políticos) e da Agência Nacional de Notícias Húngara (a qual mantém registros de todos os funcionários do governo que assumem ou deixam o cargo). Enquanto o Comitê Central do Partido Comunista é análogo ao Parlamento do subsequente período democrático, o Politburo é análogo ao papel do governo no período posterior. Nomes de detentores de cargos políticos nesses anos de 1987 a 1989 foram recolhidos de uma publicação abrangente em CD-ROM (NYíRO e SZAKADÁT, 1993).

12. Enquanto vêm sendo feitos avanços consideráveis em métodos de desenvolvimento para redes de dois modos (SKVORETZ e FAUST 1999; FIELD e outros, 2006), as rotinas de detecção de grupo desenvolvidas para dados de dois modos pressupõem que os grupos não são sobrepostos (FIELD e outros, 2006, p. 105) - uma suposição que estamos fundamentalmente questionando neste artigo.

13. A motivação para incluir tanto detentores de cargos políticos antigos como atuais vem de nossas entrevistas com gestores de grandes empresas. Como disse um CEO: "Na Hungria não existe um ex-político. Uma vez político, sempre político".

14. Não registramos um laço de pessoal entre duas empresas quando o laço é criado por um detentor de cargo político. Duas empresas podem convidar o mesmo político ou funcionário do Ministério para participar de seus conselhos, não porque querem estabelecer um laço entre eles, mas porque buscam uma conexão política e/ou governamental. Filiações políticas referem-se a laços pessoais entre partidos e empresas e não entre empresas. Incluindo um laço de pessoas entre estas empresas apresentaria ruído na informação que potencialmente anuviaria os padrões de laços pessoais criados para fomentar a colaboração nos negócios.

15. Como demonstram Everett e Borgatti, uma rede de 21 nós pode ter até 2.187 cliques. O predomínio de sobreposição nesses casos é claramente um desvio acentuado do que poderíamos pensar como processos significativos de grupo.

16. A dobra estrutural é uma propriedade do grupo e, como tal, seus benefícios são revertidos para o grupo. Para tomarmos um exemplo do cenário acadêmico: na Universidade Columbia, Charles Tilly se beneficiou de suas associações, em história e sociologia. Mas também podemos observar que o departamento de sociologia era diferente - e beneficiado como um departamento - porque tinha um membro que também era membro de outro grupo coeso.

17. A homofilia vêm sendo mostrada como um importante fator que contribui para a filiação coesa (MCPHERSON, SMITH-LOVIN e COOK, 2001). MCPHERSON e SMITH-LOVIN (2002, p. 13) definem a homofilia como sendo "o relacionamento positivo entre a similaridade (em quase qualquer dimensão) e a probabilidade de que duas pessoas terão uma conexão de rede entre elas". Embora McPherson não tenha estudado grupos de negócios, a mais pertinente dimensão de similares nesse contexto é a homogeneidade do perfil da indústria. Se a homofilia está operando entre nossas empresas húngaras, o grupos coesos concentrados na mesma indústria deveriam ser mais propensos a exibir estabilidade do que aqueles de maior heterogeneidade industrial.

18. Nosso conjunto de dados contém informações detalhadas sobre a estrutura de propriedades da empresa. Para cada empresa, podemos registrar se ela tem grande propriedade estatal e grande propriedade estrangeira, assim como detalhes no calendário de qualquer alteração de tal propriedade. Nossas definições de propriedade estatal e estrangeira significante seguem procedimentos detalhados em Stark e Vedres (2006).

\section{NOTA DA REDAÇÃo}

A RAE-revista de administração de empresas agradece ao prof. Charles Kirchsbaum por ter feito o convite aos autores Balázs Vedres e David Stark para publicar a versão em português deste artigo e também pela colaboração no processo editorial como revisor técnico.

Artigo publicado originalmente por Balázs Vedres e David Stark, sob o título Structural folds: generative disruption in overlapping groups, na American Journal of Sociology, v. 115, n. 4, January 2010. Reproduzido em língua portuguesa com a autorização dos autores e The University of Chicago Press. (OThe University of Chicago Press, 2010. www. press.uchicago.edu. 


\section{REFERÊNCIAS}

BAUM, J. A. C; MCEVILY, B; ROWLEY, T. Better with age: the longevity and the performance implications of bridging and closure. Working paper n. 1032282. Rotman School of Management, University of Toronto, 2007.

BREIGER, R. L. The duality of persons and groups. Social Forces, v. 53, n. 2, p. 181-190, 1974.

BRUDNER, L. A; WHITE, D. R. Class, property, and structural endogamy: visualizing networked histories. Theory and Society, v. 26, p. 161-208, 1997.

BURRIS, V. Interlocking directorates and political cohesion among corporate elites. American Journal of Sociology, v. 111, n. 1, p. 249-283, 2005.

BURT, R. S. Structural Holes: The Social Structure of Competition. Cambridge, MA: Harvard University Press, 1992.

BURT, R. S. Brokerage and Closure. Oxford: Oxford University Press, 2005

BURT, R. S. Information and structural holes: comment on Reagans and Zuckerman. Industrial and Corporate Change, v. 17, n. 5, p. 953-969, 2008.

DEWEY, J. The pattern of inquiry (1938). In: HICKMAN, L. A; ALEXANDER, T. M. (Eds) The Essential Dewey, v. 2, Ethics, Logic, Psychology. Bloomington, IN: Indiana University Press, 1998. p. 169-179.

DODDS, P. S; WATTS, D. J; SABEL, C. F. Information exchange and the robustness of organizational networks. Proceedings of the National Academy of Sciences, v. 100, n. 21, p.12.516-12.521, 2003.

EVERETT, M. G; BORGATTI, S. P. Analyzing clique overlap. Connections, v. 21, n, p. 49-61, 1998.

FERNANDEZ-MATEO, I. Who pays the price of brokerage? Transferring constraint through price setting in the staffing sector. American Sociological Review, v. 72, n. 2, p. 291-317, 2007.

FESTINGER, L; SCHACHTER, S; BACK, K. W. Social Pressures in Informal Groups: A Study of Human Factors in Housing. New York: Harper, 1950.

FIELD, S; FRANK, K. A; SCHILLER, K; RIEGLE-CRUMB, C; MULLER, C. Identifying positions from affiliation networks: preserving the duality of people and events. Social Networks, v. 28, n. 97-123, 2006.

FIGYELÖ. Kétszázak klubja 2001. In: Figyelö Top 200. FREEMAN, L. C. (1992). The sociological concept of "group": an empirical test of two models. American Journal of Sociology, v. 98, n. 1, p. 152-166, 2002.

FRIEDKIN, N. E. Social cohesion. Annual Review of Sociology, v. 30, p. 409-425, 2004.

GOULD, R. V. Collision of Wills: How Ambiguity about Social Rank Breeds Conflict. Chicago: University of Chicago Press, 2003.
GRANOVETTER, M. The strength of weak ties. American Journal of Sociology, v. 78, n. 6, p. 1360-1380, 1973

GRANOVETTER, M. Economic action and social structure: the problem of embeddedness. American Journal of Sociology, v. 91, n. 3, p. 481-510, 1985.

GRANOVETTER, M. Business groups and social organization. In SMELSER, N; SWEDBERG, R. (Eds) Handbook of Economic Sociology, 2 ed. Princeton, NJ: Princeton University Press; New York: Russell Sage, 2005. p. 429-450.

KHANNA, T; RIVKIN, J. W. Estimating the performance effects of business groups in emerging markets. Strategic Management Journal v. 22, p. 45-74, 2001.

KOGUT, B; ZANDER, U. Knowledge of the firm, combinative capabilities, and the replication of technology. Organization Science, v. 3, p. 383397, 1992

Lester, Richard K., and Michael J. Piore. 2004. Innovation: The Missing Dimension. Cambridge, Mass.: Harvard University Press.

LINCOLN, J. R; GERLACH, M. L; Ahmadjian, C. L. Keiretsu networks and corporate performance in Japan. American Sociological Review, v. 61, p. $67-88,1996$

MCPHERSON, M; SMITH-LOVIN, L. Cohesion and membership duration: linking groups, relations and individuals in an ecology of affiliation. Advances in Group Processes, v. 19, p. 1-36, 2002.

MCPHERSON, M; SMITH-LOVIN, L; COOK, J. M. Birds of a feather: homophily in social networks. Annual Review of Sociology, v. 27, p. 415 444,2001

MIZRUCHI, M. S. What do interlocks do? An analysis, critique, and assessment of research on interlocking directorates. Annual Review of Sociology, v. 22 , p. $271-298,1996$

MIZRUCHI, M. S; BREWSTER STEARNS, L. A longitudinal study of the formation of interlocking directorates. Administrative Science Quarterly, v. 33 , p. $194-210,1988$

MOODY, J. A; WHITE, D. R. Structural cohesion and embeddedness: a hierarchical concept of social groups. American Sociological Review 68 (1): 103-27, 2003

MORENO, J. L; JENNINGS, H. H. Statistics of social configurations. Sociometry, v. 1, n. 3/4, p. 342-374, 1937.

NYÍRÖ, A; SZAKADÁT, I. Politika Interaktiv. Budapest: Aula, 1993. CD-ROM

OBSTFELD, D. Social networks, the tertius iungens orientation, and involvement in innovation. Administrative Science Quarterly, v. 50, n. 1, p $100-130,2005$ 
PADGETT, J. F; MCLEAN, P. D. Organizational invention and elite transformation: the birth of partnership systems in renaissance Florence. American Journal of Sociology, v. 111, n. 5, p 1463-1568, 2006.

PALLA, G; DERÉNYI, I; FARKAS, I; VICSEK, T. Uncovering the overlapping community structure of complex networks in nature and society. Nature, v. 435, n. 7043, p. 814-818, 2005.

PALLA, G; BARABÁSI, A. L; VICSEK, T. Quantifying social group evolution. Nature, v. 466, n. 7136, p. 664-667, 2007.

POWELL, W. W; WHITE, D. R; KOPUT, K. W; OWEN-SMITH, J. Network dynamics and field evolution: the growth of interorganizational collaboration in the life sciences. American Journal of Sociology, v. 110. n. 4, p. 1132-1205, 2005.

SCHUMPETER, J. A. The Theory of Economic Development. Cambridge, MA: Harvard University Press, 1934.

SCHUMPETER, J. A. Essays: On entrepreneurs, innovations, business cycles, and the evolution of capitalism. New Brunswick, NJ: Transaction, 2003

SEWELL, JR; W. H. A theory of structure: duality, agency and transformation. American Journal of Sociology, v. 98, p. 1-29, 1992.

SIMMEL, G. The persistence of social groups. American Journal of Sociology, v. 3, n. 5, p. $662-698,1898$.

SIMMEL, G. (1922) Conflict and the Web of Group Affiliations. New York: Free Press, 1964.

SKVORETZ, J; FAUST, K. Logit models for affiliation networks. Sociological Methodology, v. 29, p. 253-280, 1999.

SPICER, A; MCDERMOTT, G. A; KOGUT, B. Entrepreneurship and privatization in central Europe: the tenuous balance between destruction and creation. Academy of Management Review, v. 25, p. 630-649, 2000.

STARK, D. Recombinant property in East European capitalism. American Journal of Sociology, v. 101, n. 4, p. 993-1027, 1996.

STARK, D. The Sense of Dissonance: Accounts of Worth in Economic Life. Princeton, NJ: Princeton University Press, 2009.
STARK, D; BRUSZT, L. Postsocialist Pathways: Transforming Politics and Property in East Central Europe. New York: Cambridge University Press, 1998.

STARK, D; VEDRES, B. Social times of network spaces: network sequences and foreign investment in Hungary. American Journal of Sociology, v. 111 n. 5, p. 1367-1412, 2006.

THYE, S. R; YOON, J; LAWLER, E. J. The theory of relational cohesion: review of a research program. Advances in Group Processes, v. 19 , p. 139-166, 2002.

USEEM, M. Corporations and the corporate elite. annual Review of Sociology, v. 6, p. 41-77, 1980

UZZI, B. Social structure and competition in interfirm networks: the paradox of embeddedness. Administrative Science Quarterly, v. 42, p. 35-67, 1997.

UZZI, B; SPIRO, J. Collaboration and creativity: the small world problem. American Journal of Sociology, v. 111, n. 2, p. 447-504, 2005.

WASSERMAN, S; FAUST, K. Social Network Analysis: Methods and Applications. New York: Cambridge University Press, 1994.

WATTS, D. J. Networks, dynamics and the small-world phenomenon. American Journal of Sociology, v. 105, p. 493-527, 1999.

WATTS, D. J. The "new" science of networks. Annual Review of Sociology, v. 30, p. $243-270,2004$.

WEITZMAN, M. L. Recombinant growth. Quarterly Journal of Economics, v. 113 , n. 2, p. 331-360, 1998

WHITE, D. R; JOHANSEN, U. C. Network Analysis and Ethnographic Problems: Process Models of a Turkish Nomad Clan. Lanham, MD Lexington Books, 2005.

WHITE, H. C; BOORMAN, S. A; BREIGER, R. L. Social structure from multiple networks, I: blockmodels of roles and positions. American Journal of Sociology, v. 81, n. 4, p. 730-780, 1976.

WUCHTY, S; JONES, B; UZZI, B. The increasing dominance of teams in the production of knowledge. Science, v. 316, p. 1036-1039, 2007. 